\title{
The dimeric form of CXCL12 binds to atypical chemokine receptor 1
}

\author{
Julia C. Gutjahr ${ }^{1 \dagger}$, Kyler S. Crawford ${ }^{2 \dagger}$, Davin R. Jensen ${ }^{2}$, Prachi Naik ${ }^{1}$, Francis C. Peterson ${ }^{2}$, \\ Guerric P. B. Samson ${ }^{3}$, Daniel F. Legler ${ }^{3,4}$, Johan Duchene ${ }^{5}$, Christopher T. Veldkamp ${ }^{6}$, \\ Antal Rot ${ }^{1,5,7 *}$, Brian F. Volkman ${ }^{2 *}$
}

The pleiotropic chemokine CXCL12 is involved in diverse physiological and pathophysiological processes, including embryogenesis, hematopoiesis, leukocyte migration, and tumor metastasis. It is known to engage the classical receptor CXCR4 and the atypical receptor ACKR3. Differential receptor engagement can transduce distinct cellular signals and effects as well as alter the amount of free, extracellular chemokine. CXCR4 binds both monomeric and the more commonly found dimeric forms of CXCL12, whereas ACKR3 binds monomeric forms. Here, we found that CXCL12 also bound to the atypical receptor ACKR1 (previously known as Duffy antigen/receptor for chemokines or DARC). In vitro nuclear magnetic resonance spectroscopy and isothermal titration calorimetry revealed that dimeric CXCL12 bound to the extracellular N terminus of ACKR1 with low nanomolar affinity, whereas the binding affinity of monomeric CXCL12 was orders of magnitude lower. In transfected MDCK cells and primary human Duffy-positive erythrocytes, a dimeric, but not a monomeric, construct of CXCL12 efficiently bound to and internalized with ACKR1. This interaction between CXCL12 and ACKR1 provides another layer of regulation of the multiple biological functions of CXCL12. The findings also raise the possibility that ACKR1 can bind other dimeric chemokines, thus potentially further expanding the role of ACKR1 in chemokine retention and presentation.

\section{INTRODUCTION}

Chemokines are a group of intercellular communication proteins that bind to their classical cognate $G$ protein-coupled receptors (GPCRs) to initiate different cell responses, most commonly directed migration (1). In addition, chemokines engage atypical chemokine receptors, which regulate chemokine availability in defined microenvironments by sequestering and scavenging or transporting and presenting cognate chemokines (2). Homeostatic chemokines, such as C-X-C motif chemokine ligand 12 (CXCL12), are constitutively expressed to maintain discrete cellular niches. CXCL12 is also known as stromal cell-derived factor 1 as it was first described as a pre-B cell growthstimulating factor expressed by bone marrow stromal cells (3-5). Mice deficient for CXCL12 die prenatally, showing severe developmental defects in hematopoiesis as well as defects in cardiac ventricular septa formation (6). These phenotypes of CXCL12 knockout mice are shared by mice deficient for both CXCL12 receptors, G proteincoupled CXC chemokine receptor 4 (CXCR4) $(7,8)$ and atypical chemokine receptor 3 (ACKR3) $(9,10)$. Because of the multifaceted and broad functional involvement of CXCL12, it is key to understand the mechanisms that regulate its distribution and function, including posttranslational modifications and other molecular interactions (11). Secreted CXCL12 readily forms homodimers, which have altered receptor-binding preference as compared to the monomeric

${ }^{1}$ Centre for Microvascular Research, William Harvey Research Institute, Barts and The London School of Medicine and Dentistry, Queen Mary University of London, London EC1M 6BQ, UK. ' Department of Biochemistry, Medical College of Wisconsin, Milwaukee, WI 53226, USA. ${ }^{3}$ Biotechnology Institute Thurgau (BITg), University of Konstanz, 8280 Kreuzlingen, Switzerland. ${ }^{4}$ Theodor Kocher Institute, University of Bern, 3012 Bern, Switzerland. ${ }^{5}$ Institute for Cardiovascular Prevention, LudwigMaximilians University, 80336 Munich, Germany. ${ }^{6}$ Department of Chemistry, University of Wisconsin-Whitewater, Whitewater, WI 53190, USA. ${ }^{7}$ Centre for Inflammation and Therapeutic Innovation, Barts and The London School of Medicine and Dentistry, Queen Mary University of London, London EC1M 6BQ, UK.

*Corresponding author. Email: bvolkman@mcw.edu (B.F.V.); a.rot@qmul.ac.uk (A.R.) †These authors contributed equally to this work. form and activate differential signal transduction pathways downstream of CXCR4 (12-14). Therefore, the monomer-dimer equilibrium of CXCL12 critically influences the functions of this chemokine.

ACKR1 was first found on red blood cells (RBCs) as the Duffy blood group antigen (15). It was subsequently shown to be exploited as an entry receptor for Plasmodium vivax and Plasmodium knowlesi invasion of RBCs (16-19), whereby ACKR1 induces the dimerization of its malarial parasite ligand, the Duffy-binding protein (DBP) $(20-22)$. The recognition that Duffy antigen also binds inflammatory chemokines of the CC and CXC families (23-25) led to its designation as Duffy antigen/receptor for chemokines, DARC (26), an acronym widely used until its recent classification as an ACKR (2) and subsequent inclusion in the systemic nomenclature (27). A prevalent ACKR1 polymorphism present in the majority of individuals of African ancestry abolishes its expression on RBCs (28), thus conferring a resistance to $P$. vivax and $P$. knowlesi malaria (17). In addition to RBCs and their bone marrow precursors (29), ACKR1 is also expressed by the endothelial cells $(30,31)$ of postcapillary venules $(32,33)$ and by nonvascular cells, including the Purkinje neurons of the cerebellum $(31,34)$. Individuals who lack ACKR1 on RBCs still express it in the endothelial cells and in the brain (26). ACKR1 on RBCs acts as a chemokine sink and reservoir, not only buffering the spikes in free plasma chemokines but also extending their half-life (35-38), thus shaping leukocyte responses to a broad range of chemokines, including by direct cross-competition for binding by chemokines with differential affinities for ACKR1 (39). Our study described here indicates that the paradigms of ACKR1-mediated control of chemokine availability and function can now be extended to include the regulation of CXCL12. The findings that ACKR1 has preferential affinity for CXCL12 dimers might represent an additional pathway to regulate the relative availability of the monomeric and dimeric forms of CXCL12 in distinct microenvironments of CXCL12 and ACKR1 expression $(40,41)$. 


\section{RESULTS}

\section{Protein NMR spectroscopy}

Chemokines are thought to interact with their receptors through a two-site, two-step binding and activation model, although more advanced models describe additional steps and subsidiary binding events (42-44). However, all models agree that a chemokine interacts with its receptor's extracellular $\mathrm{N}$ terminus either followed by or preceded by other interactions with different portions of its GPCR. Given the role of the chemokine receptor $\mathrm{N}$ terminus in chemokine binding, protein nuclear magnetic resonance (NMR) spectroscopy has successfully investigated the interaction of chemokines and the $\mathrm{N}$ termini of many of the signaling chemokine GPCRs (45-50). Therefore, the interaction of the $\mathrm{N}$ terminus of ACKR1 with wild-type CXCL12 (CXCL12-WT) and its locked monomeric and dimeric variants, denoted here as CXCL12-LM $(51,52)$ and CXCL12-LD $(45)$, respectively, was investigated using protein NMR. A 60-amino acid peptide corresponding to the extracellular $\mathrm{N}$ terminus of ACKR1, denoted ACKR $1^{\mathrm{N} \text {-term }}$, was expressed recombinantly and purified. Standard three-dimensional $(3 \mathrm{D})$ protein NMR techniques $(21,53)$ confirmed backbone atom assignments for $\left[\mathrm{U}_{-}{ }^{15} \mathrm{~N} /{ }^{13} \mathrm{C}\right] \mathrm{ACKR} 1{ }^{\mathrm{N} \text {-term }}$ (Fig. 1A). ${ }^{15} \mathrm{~N}-{ }^{1} \mathrm{H}$ heteronuclear single-quantum coherence (HSQC) spectra were used to monitor the titration of $\left[\mathrm{U}_{-}{ }^{15} \mathrm{~N}\right] \mathrm{ACKR} 1^{\mathrm{N}-\text { term }}$ with incremental additions of unlabeled CXCL12-LM, CXCL12-WT, or CXCL12-LD. Overlays of the spectra from the titrations (Fig. 1, B to D) show that, consistent with binding of CXCL12-WT or its variants, upon titration, many ACKR $1^{\mathrm{N} \text {-term }}$ residues exhibit chemical shift changes and/or broaden beyond detection. Markedly more ACKR1 HSQC signals broadened beyond detection after titration with CXCL12-LD than the CXCL12-WT or CXCL12-LM, suggesting differing binding properties to CXCL12 in monomeric or dimeric states. Plots of ACKR $1^{\mathrm{N} \text {-term }}$ chemical shift perturbations induced by $200 \mu$ M CXCL12-LM, CXCL12-WT, or CXCL12-LD (Fig. 1, $\mathrm{E}$ to $\mathrm{G}$ ) show that all three chemokines induced chemical shift changes or peaks that broadened beyond detection for ACKR $1^{\text {N-term }}$ residues in the $20 \mathrm{~s}$, as indicated with the stars. CXCL12-WT and, to a greater extent, CXCL12-LD lead to broadening of additional ACKR $1^{\mathrm{N} \text {-term }}$ peaks with many of these located in the $50 \mathrm{~s}$ region of ACKR $1^{\mathrm{N}-\text { term }}$ residues. Previous reports provide contradicting claims regarding the interaction or lack thereof of CXCL12 with ACKR1 $(54,55)$. Our analysis of the ACKR $1^{\mathrm{N} \text {-term }}$ spectra suggests that ACKR $1^{\mathrm{N} \text {-term }}$ can bind CXCL12-LM, CXCL12-WT, and CXCL12-LD with potentially substantial differences in affinity and stoichiometry.

To confirm ACKR $1{ }^{\mathrm{N} \text {-term }}$ binding to CXCL12, $\left[\mathrm{U}_{-}{ }^{15} \mathrm{~N}\right] \mathrm{CXCL12-}$ $\mathrm{LM},\left[\mathrm{U}_{-}{ }^{15} \mathrm{~N}\right] \mathrm{CXCL} 12-\mathrm{WT}$, and $\left[\mathrm{U}_{-}{ }^{15} \mathrm{~N}\right] \mathrm{CXCL} 12-\mathrm{LD}$ were titrated with unlabeled ACKR $1^{\mathrm{N} \text {-term }}$ and monitored by $2 \mathrm{D}$ NMR (Fig. 2, A to C). Binding of ACKR $1^{\mathrm{N} \text {-term }}$ to CXCL12-LM induced chemical shift perturbations on a fast exchange time scale with a subset of peaks showing incremental changes in chemical shift upon additions of ACKR1 ${ }^{\mathrm{N} \text {-term }}$ (Fig. 2A). CXCL12-WT exhibited a similar, but nonidentical, pattern of ACKR $1^{\mathrm{N} \text {-term }}$-induced shifts with pronounced peak broadening at intermediate titration points (Fig. 2B). In contrast to CXCL12-LM and CXCL12-WT, additions of ACKR $1^{\mathrm{N} \text {-term }}$ to CXCL12-LD produced extreme peak broadening, leading to the disappearance of many signals (Fig. 2C).

Perturbations induced by $400 \mu \mathrm{M}$ ACKR $1^{\mathrm{N} \text {-term }}$ for observable residues in CXCL12-LM, CXCL12-WT, and CXCL12-LD were quantified and revealed amino acids that broadened beyond detection (indicated with stars, Fig. 2, D to F). Chemical shift perturbations were mapped onto the structure of CXCL12 (Fig. 2G), noting Phe ${ }^{13}$ and $\mathrm{Arg}^{47}$, elements of the primary sulfotyrosine binding site of CXCL12 that is also conserved in most other chemokines (45). The predicted binding site of the $\mathrm{N}$-terminal peptide includes residues adjacent to the dimerization interface of CXCL12-WT and in the dimer overlaps the structured chemokine core, involving the adjacent $\alpha$ helices of each monomer but not residues in the chemokine $\mathrm{N}$ termini. While the chemical shifts indicate binding to all three CXCL12 variants, the interaction between $A C K R 1{ }^{\mathrm{N} \text {-term }}$ and CXCL12LD is different and, potentially, of a greater affinity than its interaction with CXCL12-LM or CXCL12-WT.

Binding events resulting in continuous NMR peak shifts (fast exchange on the chemical shift time scale) as observed for ACKR $1^{\mathrm{N} \text {-term }}$ binding to CXCL12-LM typically correspond to rapid dissociation kinetics and lower affinity (56). Slower off rates associated with intermediate exchange (CXCL12-WT) or extreme peak broadening (CXCL12-LD) are often correlated with higher binding affinities. Chemical exchange broadening in the CXCL12-WT titration could also arise from a shift in the monomer-dimer equilibrium if, for example, ACKR $1^{\mathrm{N} \text {-term }}$ bound preferentially to the CXCL12 dimeric construct. While NMR titration data are often used to estimate $K_{\mathrm{D}}$ values in the micromolar to millimolar range, the disappearance of signals from the CXCL12-LD spectrum precluded quantitative comparisons of ACKR $1^{\mathrm{N} \text {-term }}$ binding affinity to the different oligomeric states of CXCL12.

\section{High-affinity ACKR1 ${ }^{\mathrm{N} \text {-term }}$ binding to an LD construct of CXCL12}

Isothermal titration calorimetry (ITC), a sensitive technique for direct measurement of the thermodynamics of biophysical binding events, was used to further characterize the interaction between ACKR $1^{\mathrm{N} \text {-term }}$ and CXCL12 or its variants. ITC confirmed that the ACKR1 ${ }^{\text {N-term }}$ bound CXCL12-LD with higher affinity than CXCL12WT and CXCL12-LM (Fig. 3, A to C). Titration of CXCL12-LM with ACKR1 ${ }^{\mathrm{N} \text {-term }}$ did not evolve heats capable of being fitted, characteristic of a low-affinity interaction. Exothermic binding heats detected from CXCL12-WT indicating binding were fitted using the "one set of sites" binding model and yielded a mean $K_{\mathrm{D}}$ of $3480 \pm$ $831 \mathrm{nM}$ (Fig. 3D). CXCL12-LD showed an ITC isotherm with a highaffinity endothermic interaction that yielded a mean $K_{\mathrm{D}}$ of $6.23 \pm$ $0.64 \mathrm{nM}$. Given that CXCL12-WT exists in a monomer-dimer equilibrium (57), the locked monomer and locked dimer results would suggest that CXCL12-WT can bind the ACKR1 ${ }^{\mathrm{N} \text {-term }}$ tightly as a dimer but not in the monomeric state. ITC measurements estimate binding stoichiometry from the molar ratio at the transition midpoint as reported in the value of $n$, the number of sites. A value for $n$ near 1 for the interaction of ACKR1 $1^{\mathrm{N} \text {-term }}$ with CXCL12-LD reflects the 1:1 binding mode for ACKR $1^{\mathrm{N} \text {-term }}$ and the CXCL12-LD (which consists of two CXCL12 monomers linked by interior disulfide bonds), whereas $n \sim 0.5$ indicates 1:2 stoichiometry for the ACKR $1^{\mathrm{N} \text {-term }}$ :CXCL12-WT complex. Although the possibility of $\mathrm{ACKR} 1^{\mathrm{N}-\text { term }}$ binding two monomers cannot be excluded, this strongly suggests that ACKR $1^{\mathrm{N} \text {-term }}$ binding would promote dimerization of CXCL12-WT. These results are consistent with previous observations of the propensity of CXCL12 to dimerize upon binding to heparin or the CXCR4 receptor $\mathrm{N}$ terminus $(46,57)$. Together, the NMR and ITC results show that ACKR $1^{\mathrm{N} \text {-term }}$ binds CXCL12-WT and CXCL12-LD and suggests that ACKR $1^{\mathrm{N} \text {-term }}$ promotes and preferentially binds CXCL12 dimer. 

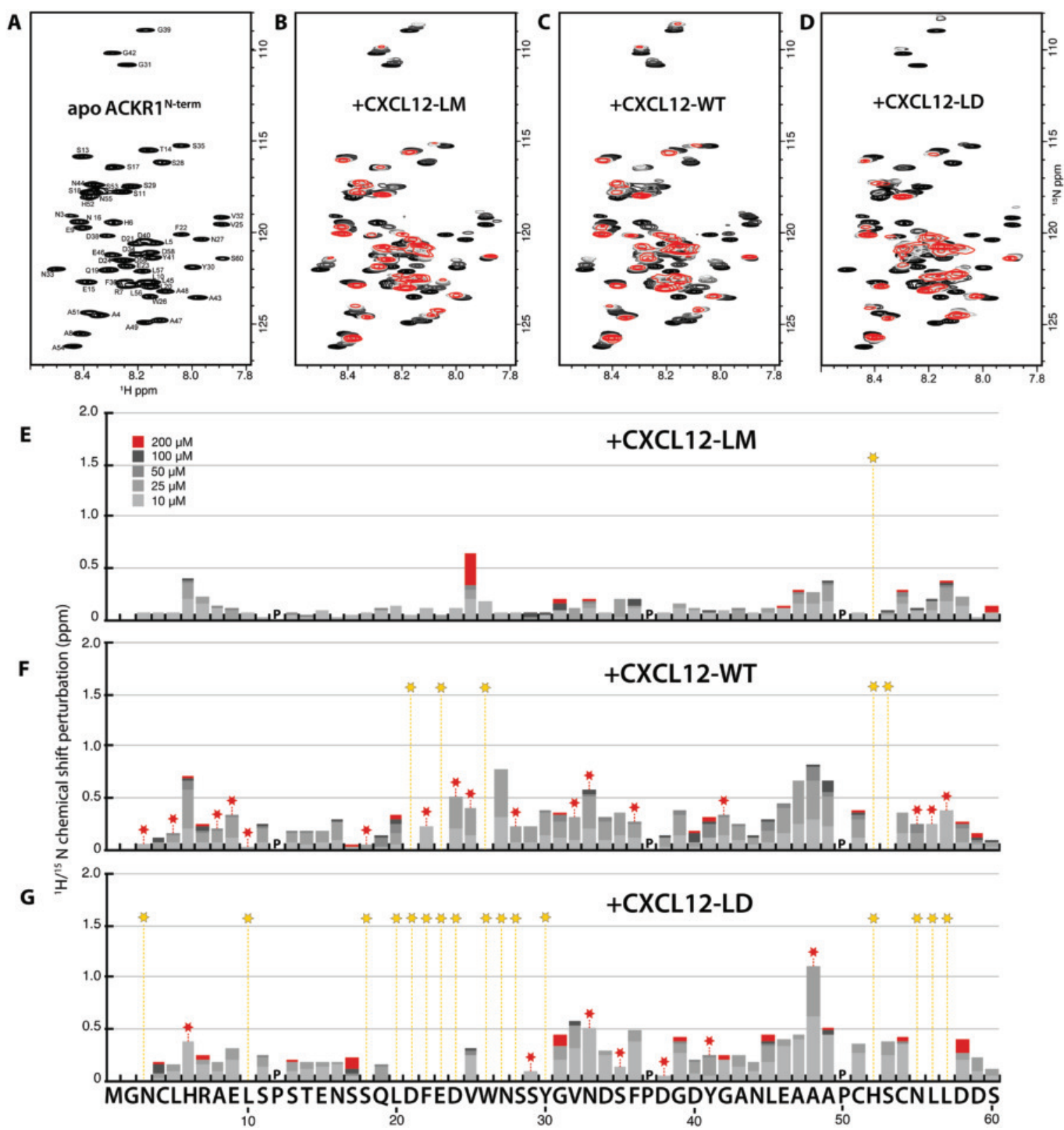

Fig. 1. ACKR1 ${ }^{\mathrm{N}-\text { term }}$ binds to CXCL12-LM, CXCL12-WT, and CXCL12-LD. (A to D) ${ }^{15} \mathrm{~N}-{ }^{1} \mathrm{H} H S Q C$ spectrum of $50 \mu \mathrm{M}^{15} \mathrm{~N}$ ACKR1 ${ }^{\mathrm{N} \text {-term }}$ alone (A) and overlaid with ${ }^{15} \mathrm{~N}-{ }^{1} \mathrm{H} H S Q C$ spectra of $50 \mu \mathrm{M}^{15} \mathrm{~N}$ ACKR1 ${ }^{\mathrm{N}-\mathrm{term}}$ alone (black) or with increasing concentrations of CXCL12-LM (B), CXCL12-WT (C), or CXCL12-LD (D) (10 to $100 \mu \mathrm{M}$ in gray shading and $200 \mu \mathrm{M}$ in red). (E to G) The resulting cumulative ACKR1 ${ }^{\mathrm{N}-\mathrm{term}}$ chemical shift perturbations induced by $200 \mu \mathrm{M}$ CXCL12-LM (E), CXCL12-WT (F), and CXCL12-LD (G) are plotted versus ACKR $1^{\mathrm{N} \text {-term }}$ residue number. Prolines and unobserved residues have a value of zero, whereas residues that broadened beyond detection during the titration or upon addition of $10 \mu \mathrm{M}$ CXCL12 are denoted with red or gold stars, respectively.

\section{CXCL12 binding to full-length cell surface ACKR1}

Next, we tested CXCL12 binding to ACKR1 expressed in a cellular system first using Madin-Darby canine kidney (MDCK) cells stably transfected with human ACKR1. Flow cytometry using a specific monoclonal antibody to human ACKR1 showed that after transfection, the MDCK cells highly expressed ACKR1 (Fig. 4A). We fluorescently labeled CC chemokine ligand 2 (CCL2), a canonical high-affinity ligand of ACKR1 $(58,59)$, with the fluorophore AZDye 647 to confirm chemokine-binding activity of ACKR1 in transfected MDCK cells. Live-cell confocal microscopy imaging and flow cytometry showed that only the ACKR1-transfected MDCK, but not the control, cells were able to bind and subsequently internalize the fluorophore-tagged CCL2-AF647 (Fig. 4, B and C).

Because the biochemical measurements indicated that ACKR1 preferentially binds CXCL12-LD, we directly labeled this chemokine with the same fluorophore (AZDye647) and used live-cell confocal imaging to compare its binding to ACKR1-transfected and control MDCK cells. CXCL12-LD-AZDye647 bound only to the ACKR1transfected MDCKs in which it initially colocalized with ACKR1 on the cell surface (Fig. 5A). Labeling ACKR1-MDCK cells with 

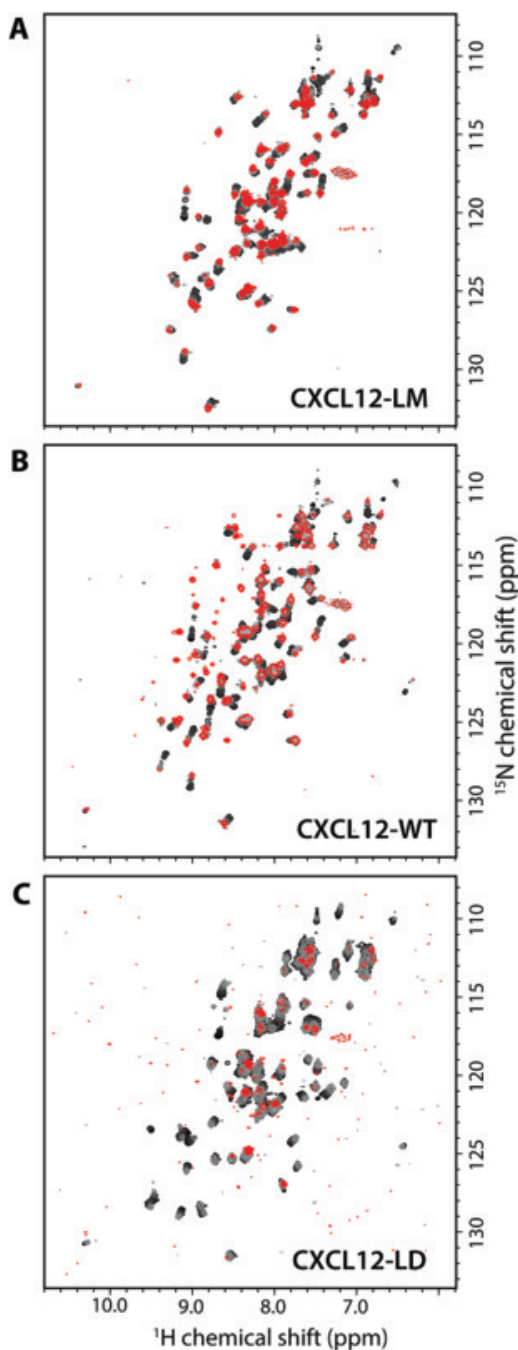

D

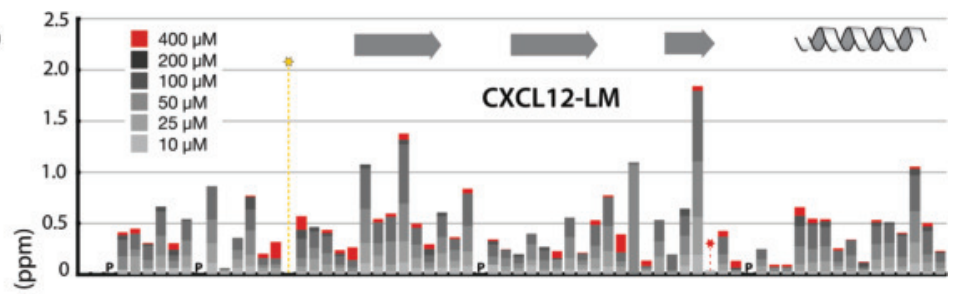

E
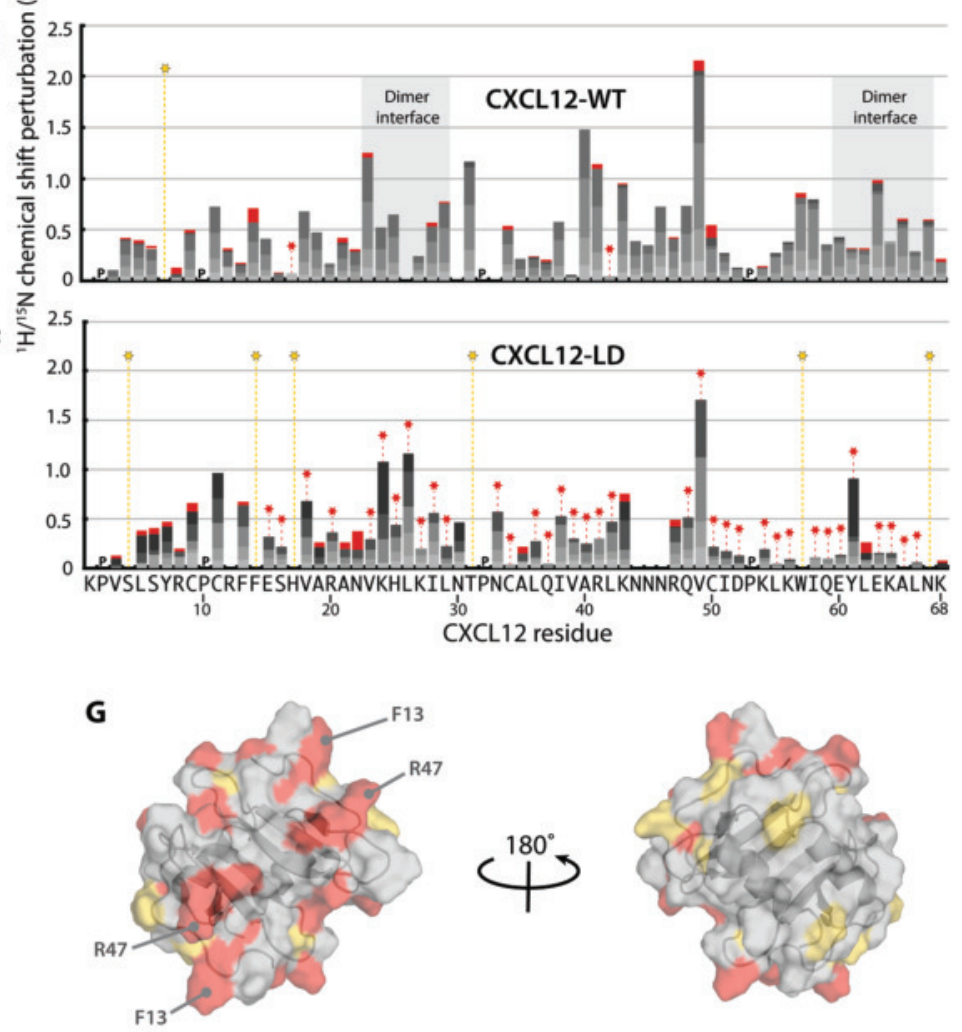

Fig. 2. ACKR1 $1^{\mathrm{N} \text {-term }}$ induced chemical shift perturbations in isotopically labeled locked monomer, wild type, or locked dimer CXCL12. (A to C) Overlays of ${ }^{15} \mathrm{~N}-{ }^{1} \mathrm{H}$ HSQC spectra of $50 \mu \mathrm{M}\left[\mathrm{U}-{ }^{15} \mathrm{~N}\right] \mathrm{CXCL12-LM}(\mathrm{A}), \mathrm{CXCL} 12-\mathrm{WT}$ (B), or CXCL12-LD (C) without (black) and with increasing concentrations of ACKR ${ }^{\mathrm{N} \text {-term }}$ (10 to $200 \mu \mathrm{M}$ in gray shading and $400 \mu \mathrm{M}$ in red). (D to F) The cumulative CXCL12-LM (D), CXCL12-WT (E), and CXCL12-LD (F) chemical shift perturbations induced by ACKR1 ${ }^{\mathrm{N}-\text { term }}$ at each step in the titration are plotted as a function of CXCL12 residue number. Residues that broadened beyond detection during the titration or upon addition of $10 \mu \mathrm{M}$ ACKR1N-term are denoted with red or gold stars, respectively. (G) Chemical shift perturbations for CXCL12-LD are highlighted in red (>0.5 ppm) or gold (disappeared at $10 \mu \mathrm{M} \mathrm{ACKR}^{\mathrm{N} \text {-term}}$ ) on the CXCL12-LD structure (Protein Data Bank: 2K01).

CXCL12-LD-AZDye647 followed by a prolonged incubation at $37^{\circ} \mathrm{C}$ led to chemokine internalization. The ACKR1 immunoreactivity remained prominently associated with the cell membranes, which at later time points were devoid of CXCL12-LD-AZDye647 found scattered intracellularly, partially colocalizing with ACKR1 (Fig. 5A). Next, we used flow cytometry to compare the binding of CXCL12LD-AZDye647 and CXCL12-WT-AZDye647 to ACKR1-deficient and ACKR1-sufficient MDCK cells. CXCL12-LD-AZDye647 associated with ACKR1-expressing MDCK cells significantly more than CXCL12-WT-AZDye647, and both chemokines bound significantly better to ACKR1-expressing MDCK cells than control MDCKs (Fig. 5B). CXCL12-LD-AZDye647 also showed higher than CXCL12WT-AZDye647 ACKR1-independent, nonspecific binding. Furthermore, the highest concentrations of both the dimeric construct and WT cross-competed, though not very efficiently, for ACKR1 binding of fluorescently labeled canonical chemokine ligand CCL2-AF647, with CXCL12-LD competing to a significantly greater extent than CXCL12-WT (Fig. 5C).

\section{Duffy-positive erythrocytes preferentially bind CXCL12-LD}

To test the interaction of CXCL12-LD-AZDye647 with ACKR1 expressed in the membranes of primary human cells, we investigated the binding of the dimeric construct CXCL12 to erythrocytes of Duffypositive individuals, which, as anticipated, showed prominent ACKR1 expression on their surface (Fig. 6A and fig. S1A). The erythrocytes of Duffy-negative individuals were used as negative controls, as these cells are practically devoid of ACKR1 expression (Fig. 6A and fig. S1A). Accordingly, Duffy-positive but not Duffy-negative erythrocytes could bind CCL2-AF647 (fig. S1B). Confocal microscopy was used to observe the pattern of CXCL12-LD-AZDye647 binding to erythrocytes of Duffy-positive and Duffy-negative individuals. Upon addition of CXCL12-LD-AZDye47 to erythrocyte suspension, fluorescence 

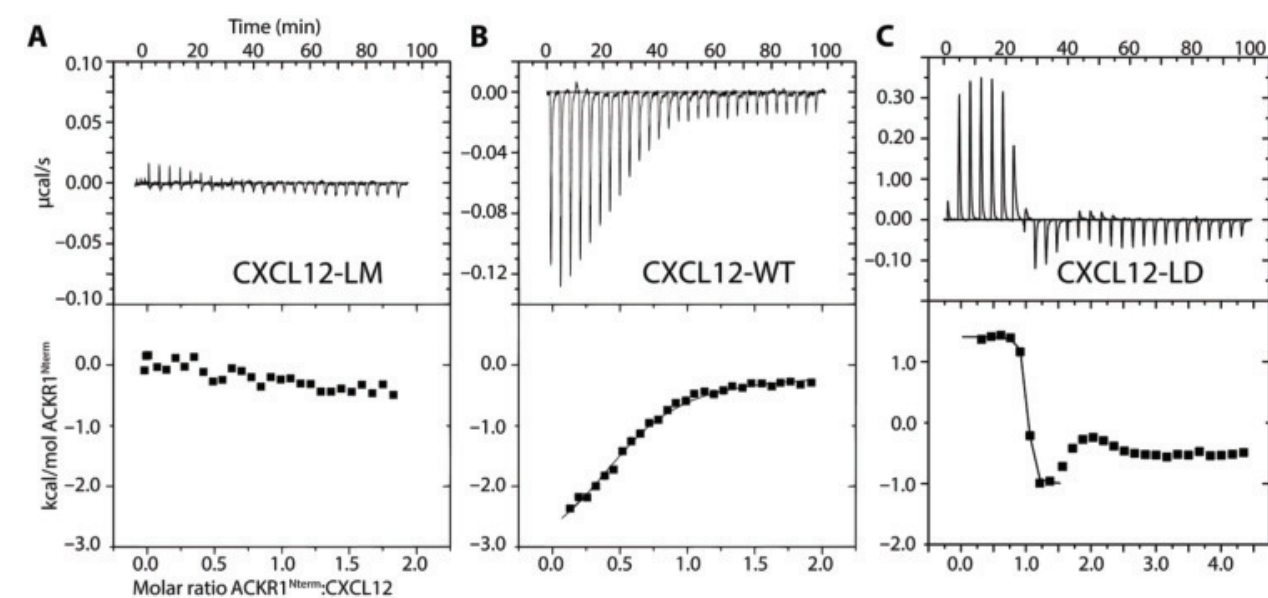

\begin{tabular}{lll} 
D \\
\hline & CXCL12-WT & CXCL12-LD \\
\hline$n$ & $0.58 \pm 0.04$ & $0.88 \pm 0.06$ \\
$\Delta H(\mathrm{cal} / \mathrm{mol})$ & $-3712 \pm 903$ & $2111 \pm 213$ \\
$\Delta S(\mathrm{cal} / \mathrm{mol} / \mathrm{deg})$ & $12.4 \pm 3.9$ & $44.0 \pm 2.5$ \\
$K_{\mathrm{D}}(\mathrm{nM})$ & $3480 \pm 831$ & $6.23 \pm 0.64$ \\
\hline
\end{tabular}

Fig. 3. ACKR1 ${ }^{\text {N-term }}$ preferentially binds CXCL12-LD. (A and B) Representative titrations from injection of (A) $200 \mu M$ ACKR1 ${ }^{\mathrm{N}-t e r m}$ into $20 \mu M$ CXCL12-LM, (B) $200 \mu M$ ACKR1 ${ }^{\mathrm{N} \text {-term }}$ into $20 \mu \mathrm{M}$ CXCL12-WT, and (C) $600 \mu \mathrm{M}$ ACKR1 ${ }^{\mathrm{N} \text {-term }}$ into $30 \mu \mathrm{M}$ CXCL12-LD. (D) Average measurements from ITC determinations obtained through fitting, using the "one set of sites" model in Origin. Data are mean \pm SD from $n=3$ experiments.

A

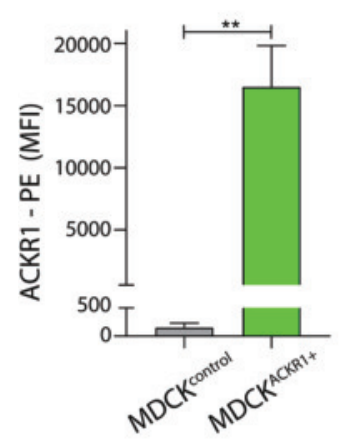

C

MDCK ${ }^{A C K R 1+}$

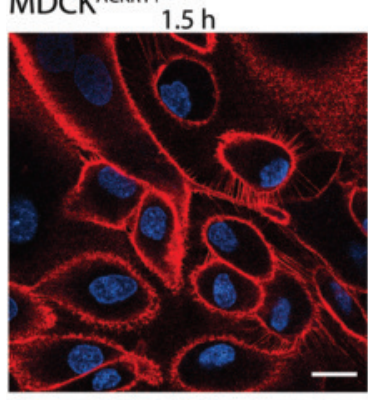

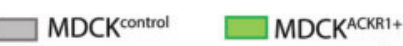

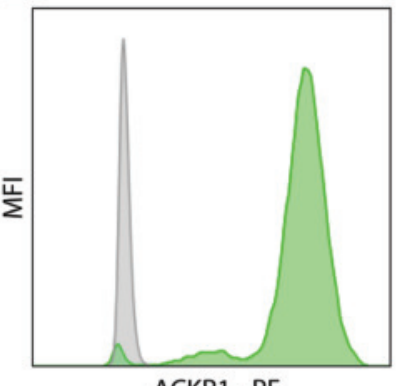

ACKR1 - PE

\section{B}

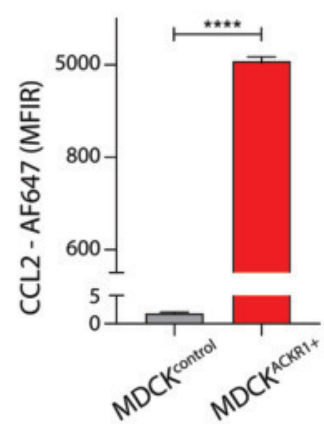

MDCK

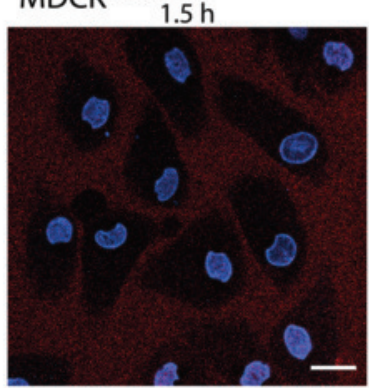

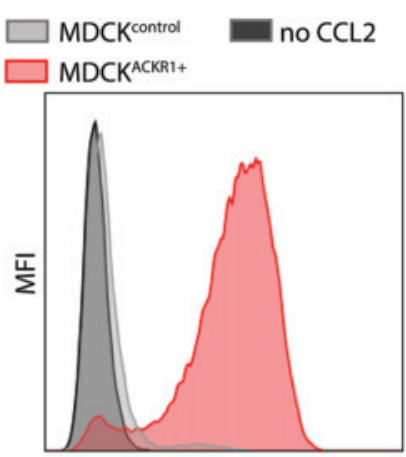

CCL2 - AF647

HOECHST CCL2 AF647
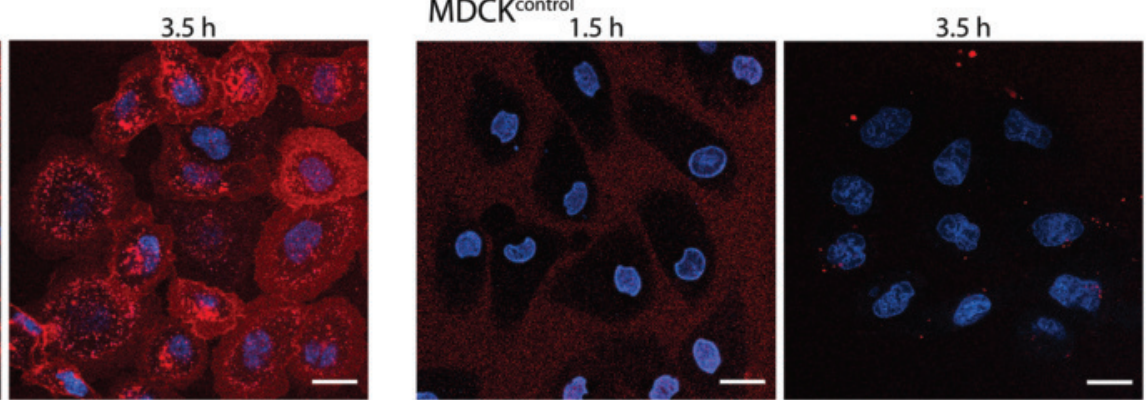

Fig. 4. Expression of ACKR1 and its binding of CCL2 in transduced MDCK cells. (A) The efficiency of ACKR1 expression in transfected MDCK $\left(M D C K^{A C K R 1+}\right)$ cells compared to wild-type parental control (MDCK ${ }^{\text {control) }}$ cells determined in flow cytometry by specific antibody to human ACKR1. Mean fluorescence intensities (MFI) \pm SD and representative histograms are shown from $n=3$ experiments. (B) Chemokine binding of ACKR1 was assessed in flow cytometry by measuring the association of fluorescently labeled canonical ligand CCL2 (20 nM CCL2-AF647) with MDCK ${ }^{A C R R 1+}$ and MDCK ${ }^{\text {Control }}$ cells. Data are shown as MFI ratios (MFIR) normalized to untreated controls \pm SD with representative histograms from $n=3$ experiments. (C) Comparison of CCL2-AF647 binding to MDCK ${ }^{A C K R 1+}$ and MDCK ${ }^{\text {Control }}$ cells under a confocal microscope. Representative images from $n=3$ experiments show the time course (h, hours) of cell binding and internalization upon incubation with $20 \mathrm{nM}$ CCL2-AF647. Scale bars, $20 \mu \mathrm{m}$. $t$ tests: ${ }^{*} P<0.01$ and ${ }^{* * *} P<0.0001$.

was initially (at $5 \mathrm{~min}$, Fig. 6A) associated with the fluid phase in both Duffy-positive and Duffy-negative samples. However, after 10-min incubation at $37^{\circ} \mathrm{C}$, fluorescent chemokine bound to Duffy-positive erythrocytes and remained associated with their surface, without signs of internalization for the 3-hour duration of the experiment (images at 1 hour shown, Fig. 6A). Conversely, CXCL12-LD-AZDye647 failed 
A
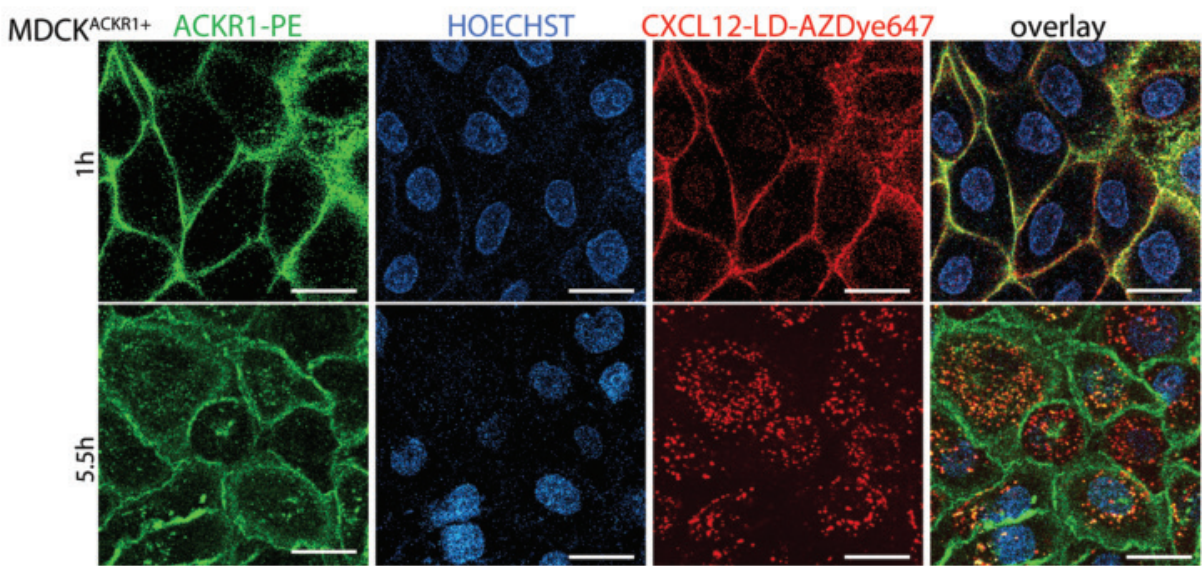

MDCK
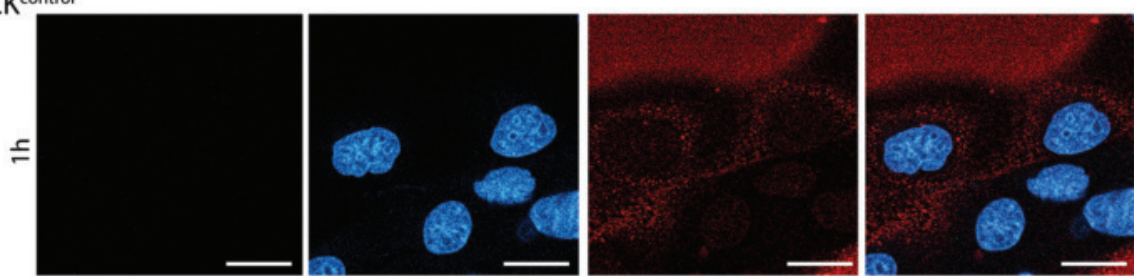

B

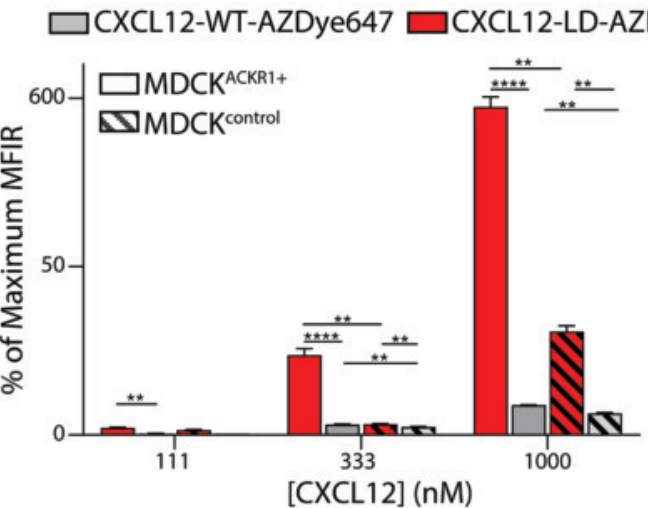

C

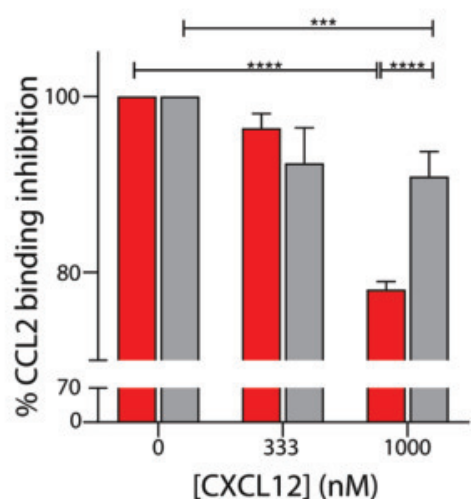

Fig. 5. CXCL12-LD binds to ACKR1 on transfected MDCK cells. (A) Time course comparison of ACKR1-dependent binding and internalization of CXCL12-LD-AZDye647 in MDCK ${ }^{A C K R 1+}$ and MDCK ${ }^{\text {control }}$ cells observed in confocal microscopy. Representative images are shown from $n=3$ experiments. Scale bars, $20 \mu \mathrm{m}$. (B) Dose-dependent binding of CXCL12-LD-AZDye647 and CXCL12-WT-AZDye647 to MDCK ${ }^{\text {ACKR1+ }}$ and MDCK ${ }^{\text {control }}$ cells as measured by flow cytometry. Percentage of maximal mean fluorescence intensity ratios (MFIR \pm SD) normalized to untreated control are shown from $n=3$ experiments. (C) Comparison of the inhibition of CCL2-AF647 (20 nM) binding to MDCK ${ }^{\text {ACKR1+ }}$ by expression of CXCL12-LD or CXCL12-WT, as measured by flow cytometry. Data are shown as percent inhibition of mean fluorescence intensity normalized to individual untreated controls \pm SD from $n=3$ experiments. Two-way ANOVA with Tukey's and Sidak's post hoc tests: ${ }^{* *} P<0.01$, ${ }^{* *} P<0.001$, and ${ }^{* * * *} P<0.0001$.

to significantly associate with Duffy-negative erythrocytes (Fig. 6A), thus illustrating the ACKR1 dependence of erythrocyte binding dimeric CXCL12.

Next, we used Duffy-positive and Duffy-negative erythrocytes to quantify and compare the ACKR1-binding capacity of fluorescently labeled CXCL12-LD-AZDye647 and CXCL12-WT-AZDye647. CXCL12-LD-AZDye647 dose-dependently associated with Duffypositive erythrocytes, while it negligibly bound to Duffy-negative erythrocytes (Fig. 6B). However, and likely due to considerable variations between individual donors, the differences were statistically significant for the highest chemokine concentration used (Fig. 6B). CXCL12-WT-AZDye647 also bound to Duffy-positive erythrocytes but significantly less so than CXCL12-LDAZDye647. Duffy-negative erythrocytes bound significantly more CXCL12-WTAZDye647 than CXCL12-LD-AZDye647, with the former binding equally well to Duffy-positive and Duffy-negative cells (Fig. 6B). Such a hierarchical pattern of ACKR1-independent erythrocyte binding of CXCL12 variants could be consistent with the involvement of CXCR4 and/or ACKR3, both receptors showing preference for the monomeric CXCL12 over the dimeric one (14). However, this is clearly not the case, as erythrocytes do not express these receptors, neither the classical CXCR4 (fig. S2) nor the atypical ACKR3 (60). The observed ACKR1independent binding of the WT chemokine theoretically could also be mediated by sulfated sugars; heparan sulfate in particular is known to interact with chemokines and impinge on their localization $(61,62)$. Heparan sulfate is expressed on erythrocyte membranes (63) but its involvement in selective binding of CXCL12WT-AZDye647 is not likely, because it preferentially binds dimeric over monomeric CXCL12 (64). It is possible that, in addition to CXCR4, ACKR3, ACKR1, and heparan sulfate, CXCL12 binds to yet another unidentified molecule present on the erythrocyte surface.

In subsequent binding competition experiments, the ACKR1-dependent erythrocyte binding of CCL2-AF647 was dose-dependently inhibited by increasing concentrations of CXCL12-LD, but not CXCL12-WT, reaching statistical significance at the highest concentration used, although, at the highest concentration tested, inhibiting only about $20 \%$ of CCL2-AF647 binding (Fig. 6C).

In conclusion, ACKR1 expressed in cellular context in transfected cells and by primary erythrocytes bound efficiently only the dimeric form of CXCL12, which also competed with CCL2 for ACKR1 binding, though not very potently or efficaciously, but significantly better than its WT counterpart. These data provide a potential explanation why previous studies on ligand specificity of ACKR1, which relied on competition binding by a series of wild-type chemokines (54), overlooked CXCL12 as a potential ligand, a potent binder as a dimer, but a relatively weak competitor, even in its dimeric form. 
A

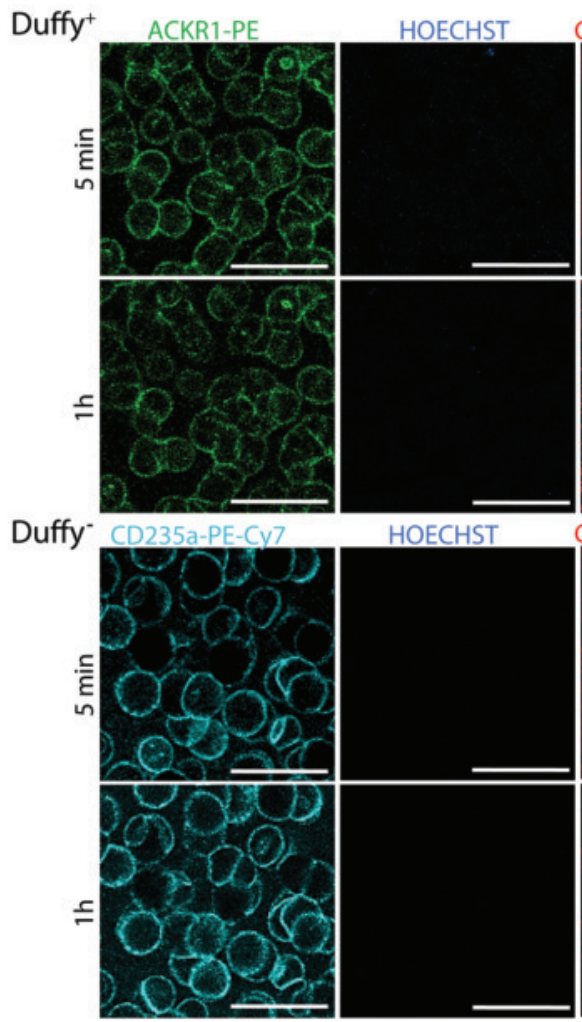

B

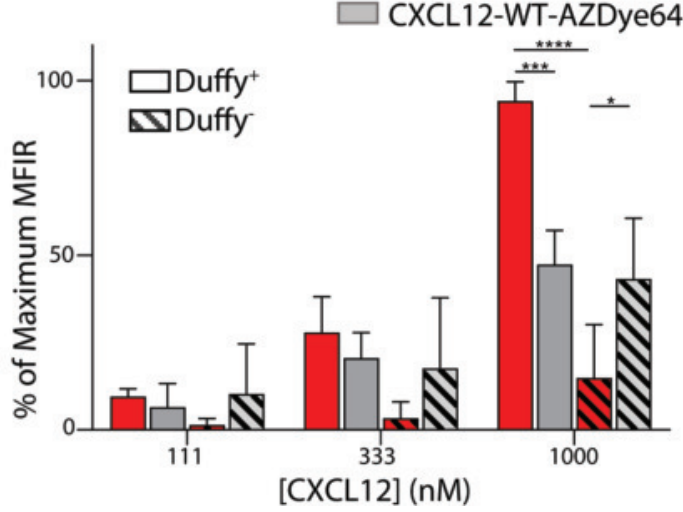

CXCL12-LD-AZDye647
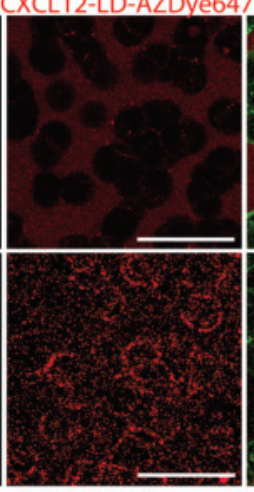

CXCL12-LD-AZDye64

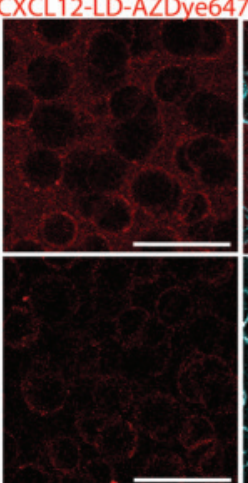

C
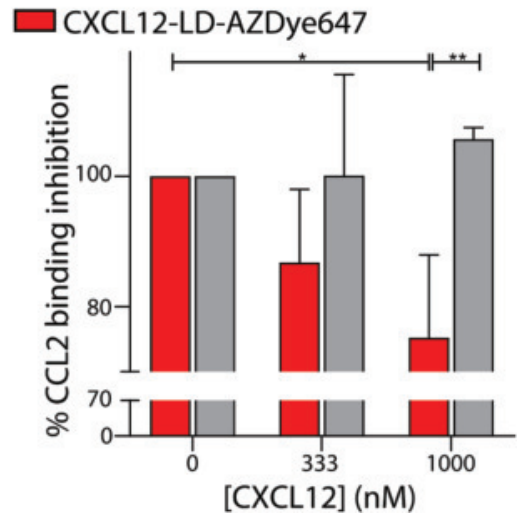

Fig. 6. ACKR1-dependent binding of CXCL12-LD to primary human erythrocytes. (A) Time course of CXCL12-LDAZDye647 interactions with primary Duffy-positive and Duffy-negative human erythrocytes as observed in confocal microscopy. Representative images are shown from $n=3$ experiments. Scale bars, $20 \mu \mathrm{m}$. (B) Dose-dependent binding of CXCL12-LD-AZDye647 and CXCL12-WT-AZDye647 to primary Duffy-positive human erythrocytes measured by flow cytometry. Data are shown as percentage of mean fluorescence intensity ratio (MFIR) normalized to the untreated controls, \pm SD from $n=3$ experiments. (C) Flow cytometry comparison of dose-dependent inhibition of CCL2AF647 (20 nM) binding to Duffy-positive erythrocytes by CXCL12-LD and CXCL12-WT. Data are shown as percent inhibition of mean fluorescence intensity normalized to individual untreated controls \pm SD from $n=3$ experiments. Two-way ANOVA with Tukey's and Sidak's post hoc tests: ${ }^{*} P<0.05,{ }^{* *} P<0.01$, ${ }^{* *} P<0.001$, and ${ }^{* * * *} P<0.0001$.

\section{DISCUSSION}

CXCL12 forms an extensive protein-protein interface with the flexible $\mathrm{N}$-terminal domain of its receptors CXCR4 and ACKR3 $(44,51,65)$. ACKR1 has the longest N-terminal domain in the chemokine receptor family (60 amino acids) and binds a multitude of inflammatory chemokines but apparently not homeostatic chemokines like
CXCL12 (54), a notion that was recently contested by Klei et al. (55). While most chemokines form dimers at micromolar concentrations or in the presence of glycosaminoglycans (66-68), they are generally understood to bind their GPCRs as monomers $(69,70)$. However, we found previously that the CXCR4 $\mathrm{N}$ terminus binds both monomeric and dimeric CXCL12 with near-equal affinity (45). Since previous surveys of chemokineACKR1 binding typically relied on measurements of competitive displacement of a high-affinity probe (e.g., CXCL8, CXCL1, or CCL2) $(29,54,71,72)$, we investigated the direct binding of CXCL12 to the ACKR1 N-terminal domain and found that ACKR1 exhibited a strong preference for binding to the dimeric form of CXCL12. Posttranslational modification of ACKR1 includes glycosylation and sulfation, facilitating oligomerization of malarial DBP $(21,73)$. In CXCR4, glycosylation of Asn $^{11}$ and sulfation of Tyr ${ }^{21}$ increase CXCL12 binding and dimerization (45, 74-76). The recombinant ACKR1 fragment produced in bacteria lacks those modifications, which are more likely to enhance CXCL12 binding than to diminish or alter it. Our findings not only confirm a recent report that CXCL12 is an ACKR1 ligand (55) but also importantly modify its conclusions as monomeric CXCL12 is not a potent ligand of ACKR1. Our data open a possibility that other chemokines that apparently fail to compete with canonical ACKR1 ligands for binding might still bind ACKR1 in physiologically relevant contexts. Furthermore, it is also possible that canonical inflammatory chemokine ligands of ACKR1 also preferentially bind in their dimeric form.

Only the ACKR1 interaction with the malarial DBP has been structurally characterized, where residues $\operatorname{Gln}^{19}$-Tyr ${ }^{30}$ bind as an $\alpha$ helix at the DBP dimer interface (21). Chemical shift perturbations suggest this region of ACKR1, which contains a cluster of acidic residues and a tyrosine $\left(\mathrm{Tyr}^{30}\right)$ conserved among orthologs that is sulfated to bind DBP oligomers, also binds CXCL12 and its locked oligomeric variants. However, ACKR1 residues between $\mathrm{His}^{52}$ and $\mathrm{Asp}^{59}$ are also implicated in the binding to CXCL12WT or CXCL12-LD. We speculate that ACKR1 uses multiple epitopes within its flexible $\mathrm{N}$ terminus to bind dimeric CXCL12 with nanomolar affinity, perhaps explaining why this interaction was overlooked in previous studies. Comparison with crystal structures of CXCR4, CCR5, and CXCR2 $(69,77,78)$ illustrates a conserved interaction 
between the receptor $\mathrm{N}$ terminus and chemokine residues forming a groove between the N-loop and 40s loop. If ACKR1 binds chemokines using different subsets of its $\mathrm{N}$-terminal domain, ligand displacement assays would likely yield variable or discordant results depending on the combination of labeled chemokine probe and competing ligand.

Mapping ACKR1-induced chemical shift perturbations onto the surface on CXCL12-LD was hampered by the disappearance of signals in the HSQC spectrum, which may be a consequence of the binding affinity and kinetics of this interaction and needs further structural basis. Residues of CXCL12-WT with the largest ACKR1induced perturbations include key CXCR4-recognition residues (such as $\mathrm{Val}^{49}$ and $\mathrm{Cys}^{50}$ ) (46), so we hypothesize that the CXCL12 receptor binding surfaces are at least partially overlapping. However, the large number of shifted CXCL12-WT HSQC peaks also includes residues $\mathrm{Val}^{23}, \mathrm{Val}^{49}$, and $\mathrm{Thr}^{31}$ bracketing the dimer interface (such as the $\beta 1$ strand and $\alpha$ helix), suggesting that ACKR1 promotes dimerization of the chemokine, consistent with the 1:2 ACKR1:CXCL12 binding stoichiometry obtained by ITC. ACKR1 binding has been reported to induce dimerization of the malarial DBP by forming contacts with both subunits at the dimer interface in the crystal structure, thus providing a potential target for antibody therapy and antimalarial vaccines $(20,22,79)$. Although ACKR1 itself has also been reported to homodimerize and heterodimerize with CCR5 (80), our stoichiometry data show that CXCL12-LD interacts with monomeric rather than dimeric ACKR1.

CXCL12 is a long-established soluble regulator of hematopoiesis that is presumed to act through its widely expressed receptor CXCR4 (6). Before the current study, we demonstrated that ACKR1 on the surface of nucleated erythroid cells also regulates hematopoiesis, but the relevant ligands had not been defined (29). Dimerization of CXCL12 is a highly relevant modification that contributes complexity to chemokine homeostasis in microenvironments with high CXCL12 concentration, such as bone marrow. While the diversity of chemokines is usually the mode of eliciting complex cellular responses through GPCRs, a precise balance of CXCL12 levels in the bone marrow modulates stem cell retention as well as healthy and malignant hematopoiesis (81). Microenvironmental conditions that favor CXCL12 dimerization may also interfere with monomeric signaling, as dimeric CXCL12 has altered CXCR4 affinity and signals through alternate pathways compared to the monomeric form. Dimeric CXCL12 induces intracellular $\mathrm{Ca}^{2+}$ flux but has no chemotactic activity and is able to block monomeric CXCL12-induced chemotaxis, suggesting its biased agonist nature $(14,45)$. Our results suggest that one of the potential unexpected new functions of ACKR1 involves binding CXCL12 dimers, thus immobilizing and/or removing them from discrete cellular microenvironments. On the basis of chemokine cross-competition binding, it is clear that in physiological settings, CXCL12 dimers are not likely to efficiently compete for ACKR1 binding with any of its high-affinity ligands. However, vice versa, the displacement of CXCL12 dimer binding by CCL2 or another high-affinity ACKR1 ligand might be a part of the ACKR1mediated regulation of CXCL12 availability by heterologous chemokines of CC and CXC families. The sites of ACKR1 expression in the bone marrow include nucleated erythroid cells, positioned in direct contact with hematopoietic stem and progenitor cells, and vascular endothelial cells of the sinusoids (29), the sites of constitutive intense cell trafficking into and from the bone marrow. We propose a hypothesis wherein, at these two distinct microanatomical sites, ACKR1 modifies the monomer-dimer equilibrium of CXCL12 and, consequently, the effects of these two CXCL12 variants in physiological and pathological hematopoiesis and bone marrow cell output. Future investigation into ACKR1 binding affinity for CXCL12 as influenced by other possible posttranslational modifications (like truncation by CD26/DPP-IV digestion) or chemokine hetero-oligomerization as well as the ability of ACKR1 to bind dimeric forms of other chemokines may uncover its additional regulatory functions in chemokine homeostasis. These findings are likely relevant for ACKR1 function in other tissues, including cerebellar neurons (82) and endothelial cells of postcapillary venules, where ACKR1 provides for optimal chemokine-induced leukocyte emigration into the tissues $(33,83)$.

\section{MATERIALS AND METHODS \\ Chemokine production}

CXCL12-WT exists in a concentration-dependent monomer-dimer equilibrium (57). CXCL12 locked monomer (CXCL12-LM) remains monomeric in isolation even at high concentrations due to L55C and I58C mutations but is structurally similar to CXCL12-WT monomer as previously described (52). CXCL12 locked dimer (CXCL12-LD) remains dimeric at low concentrations due to $\mathrm{L} 36 \mathrm{C}$ and $\mathrm{A} 65 \mathrm{C}$ mutation yet remains structurally similar to CXCL12-WT dimer, as previously described (45). CXCL12-LM, CXCL12-LD, and CXCL12WT were expressed and purified using the protocol published by Veldkamp et al. (84). The identity of CXCL12, CXCL12-LM, CXCL12$\mathrm{LD}$, and CCL2 was confirmed by linear ion trap quadrupole mass spectrometry (LTQ-MS). Lyophilized proteins were stored at $-20^{\circ} \mathrm{C}$.

CXCL12-WT, CXCL12-LD, and CCL2 were fluorescently labeled using a two-step process using sortagging (85) and copper-catalyzed azide-alkyne click chemistry. Expression plasmids for CXCL12-WT, CXCL12-LD, and CCL2 were modified using the polymerase chain reaction to contain a $\mathrm{C}$-terminal sortase $\mathrm{A}$ recognition motif with the amino acid sequence LPETGG. DNA sequence of the Sortase-tagged variants CXCL12-WT-SORT, CXCL12-LD-SORT, and CCL2-SORT expression plasmids was confirmed by DNA sequencing. Expression and purification of the SORT-containing variants was as described for the wild-type proteins (45). The identity of CXCL12-WT-SORT, CXCL12-LD-SORT, and CCL2-SORT was confirmed by LTQ-MS. Purified proteins were lyophilized and stored at $-20^{\circ} \mathrm{C}$.

Purified CXCL12-WT-SORT, CXCL12-LD-SORT, and CCL2SORT proteins were then sortagged with a five-amino acid acyl acceptor peptide having the sequence GGGWpG where $\mathrm{pG}$ is propargyl glycine. Sortagging that extends the $\mathrm{C}$ terminus of the wild-type chemokine is by nine amino acids with the sequence LPETGGGWPG. Briefly, CXCL12-WT-SORT, CXCL12-LD-SORT, or CCL2-SORT was solubilized in $50 \mathrm{mM}$ tris ( $\mathrm{pH}$ 7.4) containing $150 \mathrm{mM}$ sodium chloride and $10 \mathrm{mM}$ calcium chloride and mixed with a 2.5 molar excess of the acyl acceptor peptide. Calcium-dependent sortase A (86) was added at a molar ratio of $0.03: 1$ of sortase A:chemokine, and the reaction was incubated at $22^{\circ} \mathrm{C}$ for $15 \mathrm{~min}$. The reaction was quenched by the addition of EDTA to a final concentration of $30 \mathrm{mM}$, and the sortagged product was purified by reverse-phase high-performance liquid chromatography (HPLC) using a 21 to $42 \%$ acetonitrile gradient in $0.1 \%$ trifluoroacetic acid. Purified products were lyophilized, and their identity was confirmed by LTQ-MS.

Copper-catalyzed azide-alkyne click chemistry (87) was used to couple the azide containing fluorescent dye AZDye 647 (Click Chemistry Tools, Scottsdale, AZ) to the alkyne group present in 
propargyl glycine. Briefly, chemokines with the LPETGGGWpG extended $\mathrm{C}$ terminus were solubilized in $50 \mathrm{mM}$ Hepes ( $\mathrm{pH} 7.4$ ) and mixed with a 1.2 molar excess of AZDye 647. Reactions were run according to the protocol of Presolski et al. (87) for $15 \mathrm{~min}$ at room temperature and purified by reverse-phase HPLC using a 21 to $42 \%$ acetonitrile gradient in $0.1 \%$ trifluoracetic acid. Purified products were lyophilized, and their identity was confirmed by LTQ-MS.

\section{ACKR1 ${ }^{\mathrm{N} \text {-term }}$ production}

DNA coding for the $\mathrm{N}$ terminus of ACKR1, ACKR $1^{\mathrm{N} \text {-term }}$, consisting of residues 1 to 60 with alanine substitutions at $\mathrm{Cys}^{4}, \mathrm{Cys}^{51}$, and $\mathrm{Cys}^{54}$ was cloned into pQE30 with an N-terminal polyhistidine-SUMO fusion tag. The polyhistidine-SUMO tagged ACKR $1^{\mathrm{N} \text {-term }}$ was expressed in Escherichia coli BL21 pREP4 in 3 liters of either Luria broth or ${ }^{15} \mathrm{~N}$ or ${ }^{15} \mathrm{~N} /{ }^{13} \mathrm{C}$ M9 minimal media, with expression induced at an optical density at $600 \mathrm{~nm}$ of $0.75 \mathrm{using} 1 \mathrm{mM}$ isopropyl-beta-Dthiogalactopyranoside and growth occurring overnight at $25^{\circ} \mathrm{C}$. The cell pellet was resuspended in $30 \mathrm{ml}$ of buffer A [50 mM sodium phosphate ( $\mathrm{pH} 7.2$ ) containing $300 \mathrm{mM}$ sodium chloride, $10 \mathrm{mM}$ imidazole, $0.02 \%$ sodium azide, and protease inhibitor cocktail] and lysed with three passes through a French press or with sonication. The lysate was clarified using centrifugation $(30 \mathrm{~min}$ at $15,000 \mathrm{~g})$ and the supernatant bound to $8 \mathrm{ml}$ of nickel agarose affinity resin. The resin was washed with $50 \mathrm{ml}$ of buffer A and eluted with $14 \mathrm{ml}$ of buffer B [50 mM sodium phosphate ( $\mathrm{pH} 7.2$ ) containing $300 \mathrm{mM}$ sodium chloride, $500 \mathrm{mM}$ imidazole, and $0.02 \%$ sodium azide]. The elution was dialyzed against $50 \mathrm{mM}$ sodium phosphate ( $\mathrm{pH}$ 7.2) containing $100 \mathrm{mM}$ sodium chloride and $0.02 \%$ sodium azide overnight, and then digested with $\sim 400 \mu \mathrm{g}$ of ubiquitin-like protease ULP1. The ACKR $1^{\mathrm{N} \text {-term }}$ was separated from the polyhistidine-SUMO fusion protein by collecting the flowthrough after applying the digestion to $8 \mathrm{ml}$ of nickel agarose affinity resin. The ACKR $1^{\mathrm{N} \text {-term }}$ was further purified on a C18 column using reverse-phase HPLC eluting with increasing concentrations of acetonitrile in aqueous $0.1 \%$ trifluoroacetic acid. The eluted ACKR $1^{\mathrm{N} \text {-term }}$ was lyophilized, and its identity was confirmed by LTQ-MS. Purified protein was stored at $-20^{\circ} \mathrm{C}$.

\section{Nuclear magnetic resonance}

NMR spectroscopic data were collected at the NMR facility at the Medical College of Wisconsin on a Bruker Avance III 600-MHz spectrometer equipped with a ${ }^{1} \mathrm{H} /{ }^{13} \mathrm{C} /{ }^{15} \mathrm{~N}$ Cryoprobe at $25^{\circ} \mathrm{C}$. Backbone chemical shift assignments for the ACKR $1^{\mathrm{N}-\text { term }}(21)$ were confirmed using a $1 \mathrm{mM}\left[\mathrm{U}^{15} \mathrm{~N} /{ }^{13} \mathrm{C}\right] \mathrm{ACKR} 1^{\mathrm{N} \text {-term }}$ in NMR buffer $[20 \mathrm{mM}$ deuterated MES ( $\mathrm{pH} 6.5$ ) containing $10 \% \mathrm{D}_{2} \mathrm{O}$ and $0.02 \% \mathrm{NaN}_{3}$ ]. Standard protein NMR methods were used for assigning ACKR1 ${ }^{\mathrm{N}-\text { term }}$ amide and carbon backbone chemical shift assignments (53).

For NMR titrations, $50 \mu \mathrm{M}\left[\mathrm{U}_{-}{ }^{15} \mathrm{~N}\right] \mathrm{ACKR} 1^{\mathrm{N}-\text { term }}$ in NMR buffer was titrated with incremental additions of CXCL12-LM, CXCL12-WT, or CXCL12-LD $(0,10,25,50,75,100$, and $200 \mu \mathrm{M})$ and monitored using ${ }^{15} \mathrm{~N}-{ }^{1} \mathrm{H}$ HSQC spectra. Similarly, $50 \mu \mathrm{M}\left[\mathrm{U}_{-}{ }^{15} \mathrm{~N}\right]$ CXCL12-LM, CXCL12-WT, or CXCL12-LD was titrated with incremental additions of unlabeled ACKR1 $1^{\mathrm{N} \text {-term }}(0,25,50,75,100,200$, and $400 \mu \mathrm{M})$ and monitored using ${ }^{15} \mathrm{~N}-{ }^{1} \mathrm{H}$ HSQC spectra. Chemokine assignments were obtained from $(45,51,52,88)$.

\section{Isothermal titration calorimetry}

The ITC data were collected on a Microcal VP-ITC. Before running the experiments, all proteins and peptides were dialyzed in a SlideA-lyzer mini dialysis unit with a 2000 molecular weight cutoff against
$20 \mathrm{mM}$ MES at pH 6.5. Chemokine proteins, CXCL12-LM, CXCL12WT, or CXCL12-LD, were diluted to $20 \mu \mathrm{M}$, and ACKR $1^{\mathrm{N} \text {-term }}$ was diluted to $200 \mu \mathrm{M}$ using dialysis buffer. The chemokine solution was placed in the cell and titrated by injecting $10 \mu \mathrm{l}$ of ACKR $1^{\mathrm{N} \text {-term }}$ with a 210 -s spacing, a reference power of $10 \mu \mathrm{cal} / \mathrm{s}$, stirring of $307 \mathrm{rpm}$, and a temperature set at $26^{\circ} \mathrm{C}$. Origin software using the "one set of sites" was used for data fitting.

\section{MDCK cells}

The full-length sequence of human ACKR1 was amplified by PCR using pCMV-ACKR1 (OriGene, Rockville, MD, USA) and the specific primers (forward, 5' GACCCAAGCTTCATTACGATGGGGAACTGTCTGCACAGGG; and reverse, 5' CCGCTCTCGAGTCCACCGGATTTGCTTCCAAGGGTGTCCAG) and subcloned into the Hind III and Xho I sites of the pcDNA3 vector. MDCK cells were stably transfected with pcDNA3-ACKR1 using the Neon transfection system (Thermo Fisher Scientific). Twenty-four hours later, transfected cells were sorted into single-cell suspension based on ACKR1 expression using an ACKR1 antibody (NaM185-2C3, BD Biosciences), expanded in selection medium [G418 $(400 \mu \mathrm{g} / \mathrm{ml})]$, and re-sorted for ACKR1 expression after 1 week. Cells were further maintained in Dulbecco's minimum essential medium (DMEM) supplemented with G418 (400 $\mu \mathrm{g} / \mathrm{ml})$. Untransfected MDCK cells were used as control and cultured in DMEM. Cells showed no visible sign of contamination and have tested negative for mycoplasma.

\section{Human blood samples}

Blood was collected in EDTA-coated tubes from healthy volunteers as approved by the ethical committee of QMUL London following written consent. To determine the expression of Duffy antigen on erythrocytes, whole blood was stained with mouse monoclonal antiACKR1 (clone NaM185-2C3, BD Biosciences), mouse monoclonal anti-CXCR4 (clone 12G5, BioLegend), and mouse monoclonal antiCD235a (clone HI264, BioLegend).

\section{Chemokine binding assay}

For direct CXCL12-LD-AZDye647 binding, cells were incubated with 111,333 , or $1000 \mathrm{nM}$ CXCL12-LD-AZDye647 for $45 \mathrm{~min}$ at room temperature. Cells were washed, resuspended in flow buffer [0.4\% paraformaldehyde, $0.5 \%$ bovine serum albumin (BSA), and $2 \mathrm{mM}$ EDTA in phosphate-buffered saline (PBS)], and analyzed on a FORTESSA (BD Biosciences) flow cytometry. Mean fluorescence intensity (MFI) ratio was normalized to control baseline absent of CXCL12-LDAZDye647 and depicted as percentage of maximum MFIR.

For competitive binding assays, cells were equilibrated with unlabeled 333 or $1000 \mathrm{nM}$ CXCL12-WT or CXCL12-LD for $15 \mathrm{~min}$ at $24^{\circ} \mathrm{C}$, followed by $20 \mathrm{nM}$ CCL2-AF647 (Almac) for $45 \mathrm{~min}$ at $24^{\circ} \mathrm{C}$. Cells were washed, stained for ACKR1 or erythrocyte markers, and analyzed by flow cytometry. Specific binding of CCL2 was calculated as MFI of CCL2-AF647 (Almac)-conjugated chemokine in ACKR1 nonexpressing and expressing groups, normalized for values without competitor and depicted as mean percent inhibition.

\section{Live-cell imaging}

MDCK cells were grown overnight on glass-bottom CELLview cell culture dishes (Greiner Bio-One). Whole blood from healthy individuals was immobilized on poly-L-lysin-coated CELLview cell culture dishes. Cells were stained with HOECHST DNA dye and mouse monoclonal anti-ACKR1 (clone NaM185-2C3, BD Biosciences) where 
indicated. Cells were live-imaged in the presence of $100 \mathrm{nM}$ CCL2AF647 or $200 \mathrm{nM}$ CXCL12-LD-AZDye647 in a heat-controlled chamber at $37^{\circ} \mathrm{C}$ with $5 \% \mathrm{CO}_{2}$ in $0.5 \% \mathrm{BSA}$-containing $\mathrm{PBS}$ using a $40 \times$ oil-immersion objective and a Zeiss 800 microscope (Zeiss, Jena, Germany). Time-lapse images were acquired every $5 \mathrm{~min}$ at a step size of $1 \mu \mathrm{m}$. Experiments and analysis were performed in a nonblinded manner.

\section{Statistical analysis}

Statistics were performed using GraphPad Prism 8. Normal distribution was determined using the Kolmogorov-Smirnov test. Two normally distributed groups were compared using $t$ test. Nonparametric datasets were analyzed by Wilcoxon signed-rank tests for paired analysis or Mann-Whitney test for unpaired analysis. Grouped data were analyzed with two-way analysis of variance (ANOVA) with multiple comparison post hoc tests. Results were considered significantly different when $P<0.05$, with $P$ value thresholds designated in the figures with asterisks and defined in the legends.

\section{REFERENCES AND NOTES}

1. A. Rot, U. H. von Andrian, Chemokines in innate and adaptive host defense: Basic chemokinese grammar for immune cells. Annu. Rev. Immunol. 22, 891-928 (2004).

2. M. H. Ulvmar, E. Hub, A. Rot, Atypical chemokine receptors. Exp. Cell Res. 317, 556-568 (2011).

3. T. Nagasawa, H. Kikutani, T. Kishimoto, Molecular cloning and structure of a pre-B-cell growth-stimulating factor. Proc. Natl. Acad. Sci. U.S.A. 91, 2305-2309 (1994).

4. K. Tashiro, H. Tada, R. Heilker, M. Shirozu, T. Nakano, T. Honjo, Signal sequence trap: A cloning strategy for secreted proteins and type I membrane proteins. Science 261, 600-603 (1993).

5. A. Gomariz, P. M. Helbling, S. Isringhausen, U. Suessbier, A. Becker, A. Boss, T. Nagasawa, G. Paul, O. Goksel, G. Szekely, S. Stoma, S. F. Norrelykke, M. G. Manz, C. Nombela-Arrieta, Quantitative spatial analysis of haematopoiesis-regulating stromal cells in the bone marrow microenvironment by 3D microscopy. Nat. Commun. 9, 2532 (2018).

6. T. Nagasawa, S. Hirota, K. Tachibana, N. Takakura, S. Nishikawa, Y. Kitamura, N. Yoshida, H. Kikutani, T. Kishimoto, Defects of B-cell lymphopoiesis and bone-marrow myelopoiesis in mice lacking the CXC chemokine PBSF/SDF-1. Nature 382, 635-638 (1996).

7. Q. Ma, D. Jones, P. R. Borghesani, R. A. Segal, T. Nagasawa, T. Kishimoto, R. T. Bronson, T. A. Springer, Impaired B-lymphopoiesis, myelopoiesis, and derailed cerebellar neuron migration in CXCR4- and SDF-1-deficient mice. Proc. Natl. Acad. Sci. U.S.A. 95, 9448-9453 (1998).

8. K. Tachibana, S. Hirota, H. lizasa, H. Yoshida, K. Kawabata, Y. Kataoka, Y. Kitamura, K. Matsushima, N. Yoshida, S. Nishikawa, T. Kishimoto, T. Nagasawa, The chemokine receptor CXCR4 is essential for vascularization of the gastrointestinal tract. Nature 393 591-594 (1998).

9. F. Sierro, C. Biben, L. Martinez-Munoz, M. Mellado, R. M. Ransohoff, M. Li, B. Woehl, H. Leung, J. Groom, M. Batten, R. P. Harvey, A. C. Martinez, C. R. Mackay, F. Mackay, Disrupted cardiac development but normal hematopoiesis in mice deficient in the second CXCL12/SDF-1 receptor, CXCR7. Proc. Natl. Acad. Sci. U.S.A. 104 14759-14764 (2007)

10. H. Gerrits, D. S. van Ingen Schenau, N. E. Bakker, A. J. van Disseldorp, A. Strik, L. S. Hermens, T. B. Koenen, M. A. Krajnc-Franken, J. A. Gossen, Early postnatal lethality and cardiovascular defects in CXCR7-deficient mice. Genesis 46, 235-245 (2008).

11. R. Janssens, S. Struyf, P. Proost, The unique structural and functional features of CXCL12. Cell. Mol. Immunol. 15, 299-311 (2018).

12. P. Ray, S. A. Lewin, L. A. Mihalko, S. C. Lesher-Perez, S. Takayama, K. E. Luker, G. D. Luker, Secreted CXCL12 (SDF-1) forms dimers under physiological conditions. Biochem. J. 442, 433-442 (2012).

13. S. Fermas, F. Gonnet, A. Sutton, N. Charnaux, B. Mulloy, Y. Du, F. Baleux, R. Daniel, Sulfated oligosaccharides (heparin and fucoidan) binding and dimerization of stromal cell-derived factor-1 (SDF-1/CXCL 12) are coupled as evidenced by affinity CE-MS analysis. Glycobiology 18, 1054-1064 (2008).
14. L. J. Drury, J. J. Ziarek, S. Gravel, C. T. Veldkamp, T. Takekoshi, S. T. Hwang, N. Heveker, B. F. Volkman, M. B. Dwinell, Monomeric and dimeric CXCL12 inhibit metastasis through distinct CXCR4 interactions and signaling pathways. Proc. Natl. Acad. Sci. U.S.A. 108 17655-17660 (2011).

15. M. Cutbush, P. L. Mollison, The Duffy blood group system. Heredity 4, 383-389 (1950)

16. J. D. Haynes, J. P. Dalton, F. W. Klotz, M. H. McGinniss, T. J. Hadley, D. E. Hudson, L. H. Miller, Receptor-like specificity of a Plasmodium knowlesi malarial protein that binds to Duffy antigen ligands on erythrocytes. J. Exp. Med. 167, 1873-1881 (1988).

17. L. H. Miller, S. J. Mason, D. F. Clyde, M. H. McGinniss, The resistance factor to Plasmodium vivax in blacks. The Duffy-blood-group genotype, FyFy. N. Engl. J. Med. 295, 302-304 (1976).

18. R. Horuk, C. E. Chitnis, W. C. Darbonne, T. J. Colby, A. Rybicki, T. J. Hadley, L. H. Miller, A receptor for the malarial parasite Plasmodium vivax: The erythrocyte chemokine receptor. Science 261, 1182-1184 (1993).

19. L. H. Miller, S. J. Mason, J. A. Dvorak, M. H. McGinniss, I. K. Rothman, Erythrocyte receptors for (Plasmodium knowlesi) malaria: Duffy blood group determinants. Science 189, 561-563 (1975)

20. J. D. Batchelor, J. A. Zahm, N. H. Tolia, Dimerization of Plasmodium vivax DBP is induced upon receptor binding and drives recognition of DARC. Nat. Struct. Mol. Biol. 18, 908-914 (2011).

21. J. D. Batchelor, B. M. Malpede, N. S. Omattage, G. T. DeKoster, K. A. Henzler-Wildman N. H. Tolia, Red blood cell invasion by Plasmodium vivax: Structural basis for DBP engagement of DARC. PLOS Pathog. 10, e1003869 (2014).

22. D. Urusova, L. Carias, Y. Huang, V. C. Nicolete, J. Popovici, C. Roesch, N. D. Salinas, S. Dechavanne, B. Witkowski, M. U. Ferreira, J. H. Adams, M. L. Gross, C. L. King, N. H. Tolia, Structural basis for neutralization of Plasmodium vivax by naturally acquired human antibodies that target DBP. Nat. Microbiol. 4, 1486-1496 (2019).

23. W. C. Darbonne, G. C. Rice, M. A. Mohler, T. Apple, C. A. Hebert, A. J. Valente, J. B. Baker, Red blood cells are a sink for interleukin 8, a leukocyte chemotaxin. J. Clin. Invest. 88, 1362-1369 (1991)

24. K. Neote, J. Y. Mak, L. F. Kolakowski Jr., T. J. Schall, Functional and biochemical analysis of the cloned Duffy antigen: Identity with the red blood cell chemokine receptor. Blood 84, 44-52 (1994).

25. M. C. Szabo, K. S. Soo, A. Zlotnik, T. J. Schall, Chemokine class differences in binding to the Duffy antigen-erythrocyte chemokine receptor. J. Biol. Chem. 270, 25348-25351 (1995).

26. S. C. Peiper, Z. X. Wang, K. Neote, A. W. Martin, H. J. Showell, M. J. Conklyn, K. Ogborne, T. J. Hadley, Z. H. Lu, J. Hesselgesser, R. Horuk, The Duffy antigen/receptor for chemokines (DARC) is expressed in endothelial cells of Duffy negative individuals who lack the erythrocyte receptor. J. Exp. Med. 181, 1311-1317 (1995).

27. F. Bachelerie, G. J. Graham, M. Locati, A. Mantovani, P. M. Murphy, R. Nibbs, A. Rot, S. Sozzani, M. Thelen, New nomenclature for atypical chemokine receptors. Nat. Immunol. 15, 207-208 (2014).

28. C. Tournamille, Y. Colin, J. P. Cartron, C. Le Van Kim, Disruption of a GATA motif in the Duffy gene promoter abolishes erythroid gene expression in Duffy-negative individuals. Nat. Genet. 10, 224-228 (1995).

29. J. Duchene, I. Novitzky-Basso, A. Thiriot, M. Casanova-Acebes, M. Bianchini, S. L. Etheridge, E. Hub, K. Nitz, K. Artinger, K. Eller, J. Caamano, T. Rulicke, P. Moss, R. T. A. Megens, U. H. von Andrian, A. Hidalgo, C. Weber, A. Rot, Atypical chemokine receptor 1 on nucleated erythroid cells regulates hematopoiesis. Nat. Immunol. 18, 753-761 (2017).

30. T. J. Hadley, Z. H. Lu, K. Wasniowska, A. W. Martin, S. C. Peiper, J. Hesselgesser, R. Horuk Postcapillary venule endothelial cells in kidney express a multispecific chemokine receptor that is structurally and functionally identical to the erythroid isoform, which is the Duffy blood group antigen. J. Clin. Invest. 94, 985-991 (1994).

31. A. Chaudhuri, S. Nielsen, M. L. Elkjaer, V. Zbrzezna, F. Fang, A. O. Pogo, Detection of Duffy antigen in the plasma membranes and caveolae of vascular endothelial and epithelial cells of nonerythroid organs. Blood 89, 701-712 (1997).

32. A. Thiriot, C. Perdomo, G. Cheng, I. Novitzky-Basso, S. McArdle, J. K. Kishimoto, O. Barreiro, I. Mazo, R. Triboulet, K. Ley, A. Rot, U. H. von Andrian, Differential DARC/ACKR1 expression distinguishes venular from non-venular endothelial cells in murine tissues. BMC Biol. 15, 45 (2017).

33. M. Pruenster, L. Mudde, P. Bombosi, S. Dimitrova, M. Zsak, J. Middleton, A. Richmond, G. J. Graham, S. Segerer, R. J. Nibbs, A. Rot, The Duffy antigen receptor for chemokines transports chemokines and supports their promigratory activity. Nat. Immunol. 10, 101-108 (2009).

34. R. Horuk, A. W. Martin, Z. Wang, L. Schweitzer, A. Gerassimides, H. Guo, Z. Lu, J. Hesselgesser, H. D. Perez, J. Kim, J. Parker, T. J. Hadley, S. C. Peiper, Expression of chemokine receptors by subsets of neurons in the central nervous system. J. Immunol. 158, 2882-2890 (1997).

35. P. Jilma-Stohlawetz, M. Homoncik, C. Drucker, C. Marsik, A. Rot, W. R. Mayr, B. Seibold, B. Jilma, Fy phenotype and gender determine plasma levels of monocyte chemotactic protein. Transfusion 41, 378-381 (2001). 
36. I. G. Colditz, M. A. Schneider, M. Pruenster, A. Rot, Chemokines at large: In-vivo mechanisms of their transport, presentation and clearance. Thromb. Haemost. 97 688-693 (2007)

37. N. Fukuma, N. Akimitsu, H. Hamamoto, H. Kusuhara, Y. Sugiyama, K. Sekimizu, A role of the Duffy antigen for the maintenance of plasma chemokine concentrations. Biochem. Biophys. Res. Commun. 303, 137-139 (2003).

38. F. B. Mayr, A. O. Spiel, J. M. Leitner, C. Firbas, T. Kliegel, P. Jilma-Stohlawetz, H. Derendorf, B. Jilma, Duffy antigen modifies the chemokine response in human endotoxemia. Crit. Care Med. 36, 159-165 (2008).

39. J. Mei, Y. Liu, N. Dai, M. Favara, T. Greene, S. Jeyaseelan, M. Poncz, J. S. Lee, G. S. Worthen CXCL5 regulates chemokine scavenging and pulmonary host defense to bacterial infection. Immunity 33, 106-117 (2010).

40. A. Rot, Contribution of Duffy antigen to chemokine function. Cytokine Growth Factor Rev. 16, 687-694 (2005).

41. I. Novitzky-Basso, A. Rot, Duffy antigen receptor for chemokines and its involvement in patterning and control of inflammatory chemokines. Front. Immunol. 3, 266 (2012).

42. M. P. Crump, J. H. Gong, P. Loetscher, K. Rajarathnam, A. Amara, F. Arenzana-Seisdedos, J. L. Virelizier, M. Baggiolini, B. D. Sykes, I. Clark-Lewis, Solution structure and basis for functional activity of stromal cell-derived factor-1; dissociation of CXCR4 activation from binding and inhibition of HIV-1. EMBO J. 16, 6996-7007 (1997).

43. A. B. Kleist, A. E. Getschman, J. J. Ziarek, A. M. Nevins, P. A. Gauthier, A. Chevigne, M. Szpakowska, B. F. Volkman, New paradigms in chemokine receptor signal transduction: Moving beyond the two-site model. Biochem. Pharmacol. 114, 53-68 (2016).

44. M. Gustavsson, D. P. Dyer, C. Zhao, T. M. Handel, Kinetics of CXCL12 binding to atypical chemokine receptor 3 reveal a role for the receptor $\mathrm{N}$ terminus in chemokine binding. Sci. Signal. 12, eaaw3657 (2019).

45. C. T. Veldkamp, C. Seibert, F. C. Peterson, N. B. De la Cruz, J. C. Haugner III, H. Basnet, T. P. Sakmar, B. F. Volkman, Structural basis of CXCR4 sulfotyrosine recognition by the chemokine SDF-1/CXCL12. Sci. Signal. 1, ra4 (2008).

46. C. T. Veldkamp, C. Seibert, F. C. Peterson, T. P. Sakmar, B. F. Volkman, Recognition of a CXCR4 sulfotyrosine by the chemokine stromal cell-derived factor-1 $\alpha$ (SDF-1 $\alpha / C X C L 12)$ J. Mol. Biol. 359, 1400-1409 (2006).

47. C. J. Millard, J. P. Ludeman, M. Canals, J. L. Bridgford, M. G. Hinds, D. J. Clayton, A. Christopoulos, R. J. Payne, M. J. Stone, Structural basis of receptor sulfotyrosine recognition by a CC chemokine: The $\mathrm{N}$-terminal region of CCR3 bound to CCL11/eotaxin-1. Structure 22, 1571-1581 (2014).

48. J. H. Y. Tan, J. P. Ludeman, J. Wedderburn, M. Canals, P. Hall, S. J. Butler, D. Taleski, A. Christopoulos, M. J. Hickey, R. J. Payne, M. J. Stone, Tyrosine sulfation of chemokine receptor CCR2 enhances interactions with both monomeric and dimeric forms of the chemokine monocyte chemoattractant protein-1 (MCP-1). J. Biol. Chem. 288 , 10024-10034 (2013)

49. J. P. Ludeman, M. J. Stone, The structural role of receptor tyrosine sulfation in chemokine recognition. Br. J. Pharmacol. 171, 1167-1179 (2014).

50. M. Abayev, J. Rodrigues, G. Srivastava, B. Arshava, L. Jaremko, M. Jaremko, F. Naider, M. Levitt, J. Anglister, The solution structure of monomeric CCL5 in complex with a doubly sulfated N-terminal segment of CCR5. FEBS J. 285, 1988-2003 (2018).

51. J. J. Ziarek, A. B. Kleist, N. London, B. Raveh, N. Montpas, J. Bonneterre, G. St-Onge, C. J. DiCosmo-Ponticello, C. A. Koplinski, I. Roy, B. Stephens, S. Thelen, C. T. Veldkamp, F. D. Coffman, M. C. Cohen, M. B. Dwinell, M. Thelen, F. C. Peterson, N. Heveker, B. F. Volkman, Structural basis for chemokine recognition by a $\mathrm{G}$ protein-coupled receptor and implications for receptor activation. Sci. Signal. 10, eaah5756 (2017)

52. J. J. Ziarek, A. E. Getschman, S. J. Butler, D. Taleski, B. Stephens, I. Kufareva, T. M. Handel, R. J. Payne, B. F. Volkman, Sulfopeptide probes of the CXCR4/CXCL12 interface reveal oligomer-specific contacts and chemokine allostery. ACS Chem. Biol. 8, 1955-1963 (2013).

53. J. L. Markley, E. L. Ulrich, W. M. Westler, B. F. Volkman, Macromolecular structure determination by NMR spectroscopy. Methods Biochem. Anal. 44, 89-113 (2003).

54. L. Gardner, A. M. Patterson, B. A. Ashton, M. A. Stone, J. Middleton, The human Duffy antigen binds selected inflammatory but not homeostatic chemokines. Biochem. Biophys. Res. Commun. 321, 306-312 (2004).

55. T. R. L. Klei, F. Aglialoro, F. P. J. Mul, S. Tol, P. C. Ligthart, I. M. Seignette, J. Geissler, E. van den Akker, R. van Bruggen, Differential interaction between DARC and SDF-1 on erythrocytes and their precursors. Sci. Rep. 9, 16245 (2019).

56. A. G. Palmer III, Chemical exchange in biomacromolecules: Past, present, and future. J. Magn. Reson. 241, 3-17 (2014).

57. C. T. Veldkamp, F. C. Peterson, A. J. Pelzek, B. F. Volkman, The monomer-dimer equilibrium of stromal cell-derived factor-1 (CXCL 12) is altered by $\mathrm{pH}$, phosphate, sulfate, and heparin. Protein Sci. 14, 1071-1081 (2005).

58. A. Rot, In situ binding assay for studying chemokine interactions with endothelial cells. J. Immunol. Methods 273, 63-71 (2003).
59. S. Apostolakis, G. K. Chalikias, D. N. Tziakas, S. Konstantinides, Erythrocyte Duffy antigen receptor for chemokines (DARC): Diagnostic and therapeutic implications in atherosclerotic cardiovascular disease. Acta Pharmacol. Sin. 32, 417-424 (2011).

60. R. Ameti, S. Melgrati, E. Radice, E. Cameroni, E. Hub, S. Thelen, A. Rot, M. Thelen, Characterization of a chimeric chemokine as a specific ligand for ACKR3. J. Leukoc. Biol. 104, 391-400 (2018)

61. L. M. Webb, M. U. Ehrengruber, I. Clark-Lewis, M. Baggiolini, A. Rot, Binding to heparan sulfate or heparin enhances neutrophil responses to interleukin 8. Proc. Natl. Acad. Sci. U.S.A. 90, 7158-7162 (1993).

62. A. Rot, Chemokine patterning by glycosaminoglycans and interceptors. Front. Biosci. (Landmark Ed) 15, 645-660 (2010).

63. A. M. Vogt, G. Winter, M. Wahlgren, D. Spillmann, Heparan sulphate identified on human erythrocytes: A Plasmodium falciparum receptor. Biochem. J. 381, 593-597 (2004)

64. J. J. Ziarek, C. T. Veldkamp, F. Zhang, N. J. Murray, G. A. Kartz, X. Liang, J. Su, J. E. Baker, R. J. Linhardt, B. F. Volkman, Heparin oligosaccharides inhibit chemokine (CXC motif) ligand 12 (CXCL12) cardioprotection by binding orthogonal to the dimerization interface, promoting oligomerization, and competing with the chemokine (CXC motif) receptor 4 (CXCR4) N terminus. J. Biol. Chem. 288, 737-746 (2013).

65. M. Gustavsson, L. Wang, N. van Gils, B. S. Stephens, P. Zhang, T. J. Schall, S. Yang, R. Abagyan, M. R. Chance, I. Kufareva, T. M. Handel, Structural basis of ligand interaction with atypical chemokine receptor 3. Nat. Commun. 8, 14135 (2017).

66. A. E. I. Proudfoot, Z. Johnson, P. Bonvin, T. M. Handel, Glycosaminoglycan interactions with chemokines add complexity to a complex system. Pharmaceuticals 10, (2017).

67. C. L. Salanga, T. M. Handel, Chemokine oligomerization and interactions with receptors and glycosaminoglycans: The role of structural dynamics in function. Exp. Cell Res. 317, 590-601 (2011).

68. W. G. Liang, C. G. Triandafillou, T. Y. Huang, M. M. Zulueta, S. Banerjee, A. R. Dinner, S. C. Hung, W. J. Tang, Structural basis for oligomerization and glycosaminoglycan binding of CCL5 and CCL3. Proc. Natl. Acad. Sci. U.S.A. 113, 5000-5005 (2016).

69. L. Qin, I. Kufareva, L. G. Holden, C. Wang, Y. Zheng, C. Zhao, G. Fenalti, H. Wu, G. W. Han, V. Cherezov, R. Abagyan, R. C. Stevens, T. M. Handel, Structural biology. Crystal structure of the chemokine receptor CXCR4 in complex with a viral chemokine. Science $\mathbf{3 4 7}$ 1117-1122 (2015)

70. B. Wu, E. Y. Chien, C. D. Mol, G. Fenalti, W. Liu, V. Katritch, R. Abagyan, A. Brooun, P. Wells, F. C. Bi, D. J. Hamel, P. Kuhn, T. M. Handel, V. Cherezov, R. C. Stevens, Structures of the CXCR4 chemokine GPCR with small-molecule and cyclic peptide antagonists. Science 330, 1066-1071 (2010)

71. C. Tournamille, C. Le Van Kim, P. Gane, D. Blanchard, A. E. Proudfoot, J. P. Cartron, Y. Colin, Close association of the first and fourth extracellular domains of the Duffy antigen receptor for chemokines by a disulfide bond is required for ligand binding. J. Biol. Chem. 272, 16274-16280 (1997).

72. M. Kashiwazaki, T. Tanaka, H. Kanda, Y. Ebisuno, D. Izawa, N. Fukuma, N. Akimitsu, K. Sekimizu, M. Monden, M. Miyasaka, A high endothelial venule-expressing promiscuous chemokine receptor DARC can bind inflammatory, but not lymphoid, chemokines and is dispensable for lymphocyte homing under physiological conditions. Int. Immunol. 15, 1219-1227 (2003).

73. M. Czerwinski, J. Kern, M. Grodecka, M. Paprocka, A. Krop-Watorek, K. Wasniowska, Mutational analysis of the $\mathrm{N}$-glycosylation sites of Duffy antigen/receptor for chemokines. Biochem. Biophys. Res. Commun. 356, 816-821 (2007).

74. J. Wang, G. J. Babcock, H. Choe, M. Farzan, J. Sodroski, D. Gabuzda, N-linked glycosylation in the CXCR4 N-terminus inhibits binding to HIV-1 envelope glycoproteins. Virology 324, 140-150 (2004).

75. D. J. Chabot, H. Chen, D. S. Dimitrov, C. C. Broder, N-linked glycosylation of CXCR4 masks coreceptor function for CCR5-dependent human immunodeficiency virus type 1 isolates. J. Virol. 74, 4404-4413 (2000).

76. M. Farzan, G. J. Babcock, N. Vasilieva, P. L. Wright, E. Kiprilov, T. Mirzabekov, H. Choe, The role of post-translational modifications of the CXCR4 amino terminus in stromal-derived factor $1 \alpha$ association and HIV-1 entry. J. Biol. Chem. 277, 29484-29489 (2002).

77. Y. Zheng, G. W. Han, R. Abagyan, B. Wu, R. C. Stevens, V. Cherezov, I. Kufareva, T. M. Handel, Structure of CC chemokine receptor 5 with a potent chemokine antagonist reveals mechanisms of chemokine recognition and molecular mimicry by HIV. Immunity 46, 1005-1017.e5 (2017).

78. K. Liu, L. Wu, S. Yuan, M. Wu, Y. Xu, Q. Sun, S. Li, S. Zhao, T. Hua, Z. J. Liu, Structural basis of CXC chemokine receptor 2 activation and signalling. Nature 585, 135-140 (2020)

79. S. Sampath, C. Carrico, J. Janes, S. Gurumoorthy, C. Gibson, M. Melcher, C. E. Chitnis, R. Wang, W. R. Schief, J. D. Smith, Glycan masking of Plasmodium vivax Duffy binding protein for probing protein binding function and vaccine development. PLOS Pathog. 9 , e1003420 (2013). 
80. A. Chakera, R. M. Seeber, A. E. John, K. A. Eidne, D. R. Greaves, The duffy antigen/recepto for chemokines exists in an oligomeric form in living cells and functionally antagonizes CCR5 signaling through hetero-oligomerization. Mol. Pharmacol. 73, 1362-1370 (2008).

81. P. Agarwal, S. Isringhausen, H. Li, A. J. Paterson, J. He, A. Gomariz, T. Nagasawa, C. Nombela-Arrieta, R. Bhatia, Mesenchymal niche-specific expression of Cxcl12 controls quiescence of treatment-resistant leukemia stem cells. Cell Stem Cell 24, 769-784.e6 (2019).

82. E. H. Schneider, S. C. Fowler, M. S. Lionakis, M. Swamydas, G. Holmes, V. Diaz, J. Munasinghe, S. C. Peiper, J. L. Gao, P. M. Murphy, Regulation of motor function and behavior by atypical chemokine receptor 1. Behav. Genet. 44, 498-515 (2014).

83. T. Girbl, T. Lenn, L. Perez, L. Rolas, A. Barkaway, A. Thiriot, C. Del Fresno, E. Lynam, E. Hub, M. Thelen, G. Graham, R. Alon, D. Sancho, U. H. von Andrian, M. B. Voisin, A. Rot, S. Nourshargh, Distinct compartmentalization of the chemokines $\mathrm{CXCL} 1$ and $\mathrm{CXCL2}$ and the atypical receptor ACKR1 determine discrete stages of neutrophil diapedesis. Immunity 49, 1062-1076.e6 (2018).

84. C. T. Veldkamp, C. A. Koplinski, D. R. Jensen, F. C. Peterson, K. M. Smits, B. L. Smith, S. K. Johnson, C. Lettieri, W. G. Buchholz, J. C. Solheim, B. F. Volkman, Production of recombinant chemokines and validation of refolding. Methods Enzymol. 570, 539-565 (2016).

85. J. M. Antos, M. C. Truttmann, H. L. Ploegh, Recent advances in sortase-catalyzed ligation methodology. Curr. Opin. Struct. Biol. 38, 111-118 (2016).

86. I. Chen, B. M. Dorr, D. R. Liu, A general strategy for the evolution of bond-forming enzymes using yeast display. Proc. Natl. Acad. Sci. U.S.A. 108, 11399-11404 (2011).

87. S. I. Presolski, V. P. Hong, M. G. Finn, Copper-catalyzed azide-alkyne click chemistry for bioconjugation. Curr. Protoc. Chem. Biol. 3, 153-162 (2011).

88. C. T. Veldkamp, J. J. Ziarek, J. Su, H. Basnet, R. Lennertz, J. J. Weiner, F. C. Peterson, J. E. Baker, B. F. Volkman, Monomeric structure of the cardioprotective chemokine SDF-1/CXCL12. Protein Sci. 18, 1359-1369 (2009).
Acknowledgments: We thank R. Saleeb, CMR Advanced Bio-Imaging Facility, QMUL, for expert assistance with the confocal microscopy studies, and we thank P. E. Adogamhe and G. J. Cordova of UW-Whitewater for technical assistance. Funding: This work was supported by the Wellcome Trust Investigator Award 200817/Z/16/Z to A.R.; Sinergia grant of the Swiss National Science Foundation CRSII3 160719 to D.F.L. and A.R.; Versus Arthritis Endowment to A.R.; Deutsche Forschungsgemeinschaft grant SFB1123-A10 to J.D.; NIH (USA) research grant R01 Al058072 to B.F.V., shared instrumentation grant S10 OD020000, and training grant T32 GM080202 to K.S.C. Author contributions: The study was conceived and designed by J.C.G., C.T.V., A.R., and B.F.V. Methodology was developed by J.C.G., C.T.V., K.S.C., F.C.P., G.P.B.S., and D.F.L. The data were acquired by J.C.G., K.S.C., D.R.J., P.N., F.C.P., G.P.B.S., and C.T.V. and analyzed and interpreted by J.C.G., K.S.C., D.R.J., P.N., F.C.P., G.P.B.S., D.F.L., J.D., C.T.V., A.R., and B.F.V. The manuscript was written by J.C.G., K.S.C., C.T.V., A.R., and B.F.V. with revision assistance from D.R.J., P.N., F.C.P., G.P.B.S., D.F.L., and J.D. Administrative, technical, or material support was provided by D.F.L., A.R., and B.F.V. Correspondence was handled by A.R. and B.F.V. Competing interests: B.F.V. and F.C.P. have ownership interests in Protein Foundry. All other authors declare that they have no competing interests. 